\title{
Investigation of wellbore microannulus permeability under stress via experimental wellbore mock-up and finite element modeling
}

\author{
Steven P. Gomez ${ }^{1,2 *}$, Steve R. Sobolik ${ }^{2}$, Edward N. Matteo ${ }^{2}$, Mahmoud Reda Taha ${ }^{1}$ and \\ John C. Stormont ${ }^{1}$ \\ 1 University of New Mexico, Dept. of Civil Engineering, Albuquerque, NM \\ ${ }^{2}$ Sandia National Laboratories, Albuquerque, NM \\ ${ }^{*}$ Corresponding Author (current affiliation): \\ Steven P. Gomez \\ Sandia National Labs \\ Tel: +1 5052842333 \\ spgomez@sandia.gov
}

\begin{abstract}
$\underline{\text { Abstract }}$
This research aims to describe the microannulus region of the cement sheath-steel casing interface in terms of its compressibility and permeability. A wellbore system mock-up was used for lab-scale testing, and was subjected to confining and casing pressures in a pressure vessel while measuring gas flow along the specimen's axis. The flow was interpreted as the hydraulic aperture of the microannuli. Numerical joint models were used to calculate stress and displacement conditions of the microannulus region, where the mechanical stiffness and hydraulic aperture were altered in response to the imposed stress state and displacement across the joint interface.
\end{abstract}

\section{1: Introduction}

Subsurface geologic formations can be used as a storage reservoir for $\mathrm{CO}_{2}$. Abandioned wellbores within the areal extent of the injection plume can potentially can ppoten tially a pathway for leakage and/or migration. Characterizing wellbore integrity and providing zonal isolation by repairing these wellbore flaws is of critical importance to the longterm isolation of $\mathrm{CO}_{2}$ and success of CCS. Debonding between between the wellbore cement sheath and the steel casing (so-called "micorannuli") can be remediated via injection of seal repair materials with the intention of restoring seal integrity to the wellbore (Bellabara, 2008). In order to design seal repair materials that provide a durable restoration of seal integrity, fundamental understanding of mechanical evolution of microannuli under varying confining and casing pressure is critical.

Wellbore integrity is compromised by flaws that arise from a number of different causes, including inadequate cement-formation and cement-casing bonds, cement 
shrinkage, formation of a microannulus at the casing-cement interface, fracture formation within the cement, poorly emplaced cement, incomplete removal of drilling mud from casing prior to cementing, clay washouts at caprock interfaces, and others (Bois et al., 2012; Carey et al., 2013). The cement sheath is also potentially susceptible to acid degradation introduced by carbonated brine flowing from the formation and either onto the bottom of the cement plug or into the annular space of the cement sheath-steel casing interface (Kutchko et al., 2007; Matteo and Scherer, 2012). Flaws in wellbore systems are schematically represented in Figure 1.

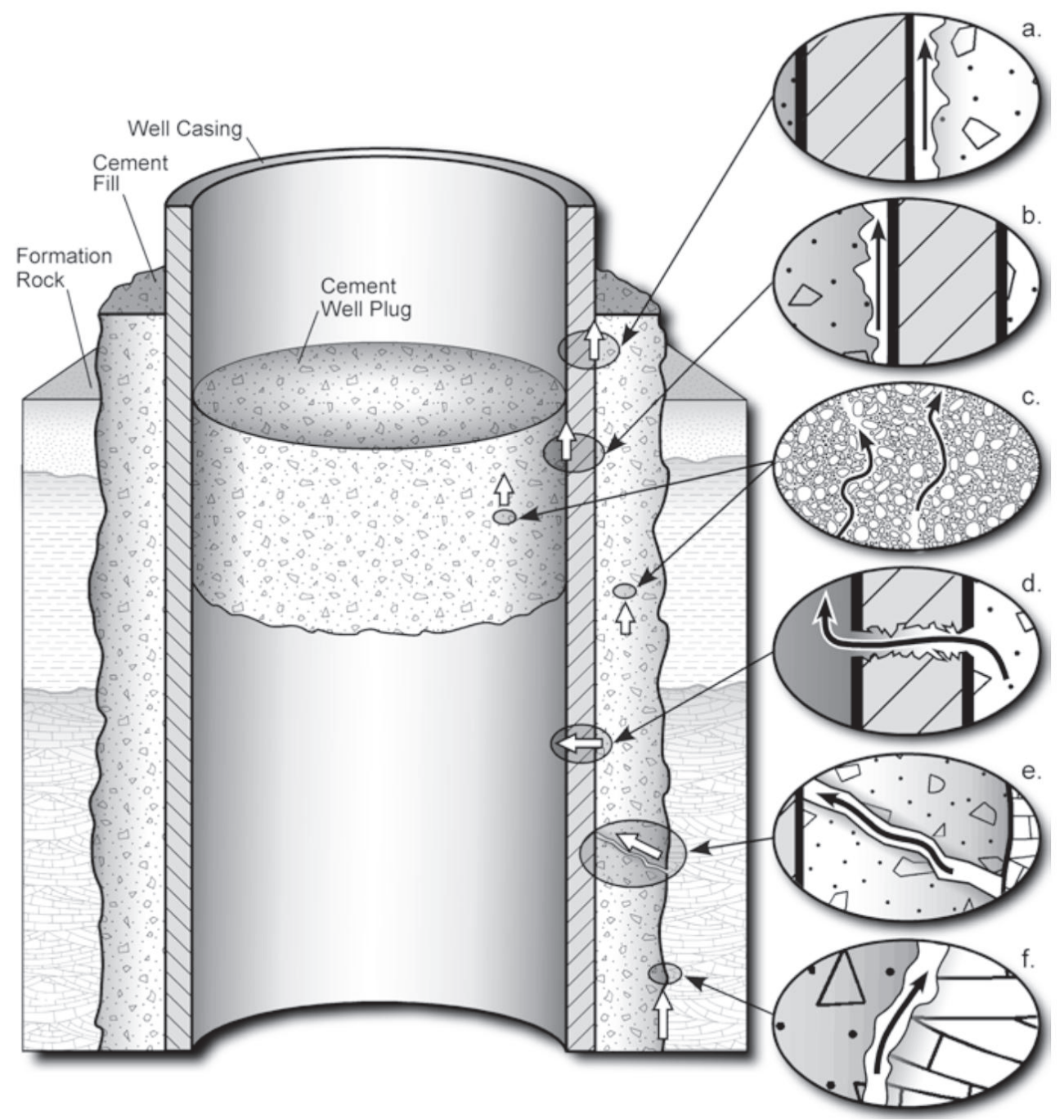

Figure 1: Wellbore leakage pathways of concern: (a) and (b) between cement and casing, (c) through the cement, (d) through the casing, (e) through fractures, and (f) between cement and formation (Gasda et al, 2004)

The cement-casing interface, herein referred to as the microannulus, has been identified as a common leakage pathway (Bellabara, 2008; Bachu and Bennion, 2009; Zhang and Bachu, 2011). It is not clear a priori how microannulus permeability will respond, if at all, 
to stress changes that are likely to occur as a result of $\mathrm{CO}_{2}$ injection or from other subsurface events. These stresses could include changes in internal pressures in the casing, as well as confining stresses from the host formation(s) surrounding the the wellbore system. The external stresses that act on the cement sheath are a function of many factors, including the overburden pressure, the tendency of the rock to creep, deformations in the overburden and wellbore systems due to reservoir compaction or expansion, changes in formation pore pressure, expansion/contraction of the cement, and pressures and temperatures in the casing (Hawkes et al., 2005; Orlic, 2008). The pressure within a casing can also vary, depending on the condition and use of the wellbore. In an abandoned well, the casing pressure will depend on what material (water, mud, cement), if any, remains in the casing. While in operation, an injection well will have a casing pressure in excess of the formation pore pressure, but less than the formation breakdown pressure to prevent formation failure. The contact stress across the cement-casing interface depends in part on the casing pressure. Temperature changes in the casing fluids may also induce casing expansion and contraction, imposing stresses on the cement-casing interface (Lavrov et al., 2015).

Understanding of microannulus flow as a function of stress is critical to a number of applications. Estimates of flow through a leaky wellbore with a microannulus will be improved if the stress conditions that are possible for a particular well are taken into account. The impact of well operations on wellbore integrity could be better understood and perhaps managed if the microannulus response to stress was understood. This knowledge would also inform efforts to repair leaky wellbores that often involve attempts to "squeeze" repair materials into the microannulus in order to restore the functionality of the wellbore. Small wellbore microannuli on the order of 25 microns have shown to be a sufficient size to permit a gaseous flow path (Seidel and Greene 1985).

Numerical modelers are endeavoring to represent more complex constitutive laws that have been used to simulate viscoplastic rate dependence and non-linear hardening effects of geological rocks, cement, and other brittle materials (Brannon et al., 2009; Martinez et al., 2013) as well as cement slurry hardening, shrinkage, pore pressure effects on dynamic $\mathrm{CO}_{2}$ injection process and subsequent rock fracture (Gray et al., 2009; Carey et al., 2013; Martinez et al., 2013). Cement sheath behavior has been modeled using Finite Element Analysis (FEA) which includes formation imposed far field stresses, cement shrinkage and expansion, hardening, interfacial debonding, and wellbore life time-history characterstics that give insight to cumulative effects on prospective damage and fracture (Ravi et al., 2002; Gray et al., 2009). Gray et al. (2009) allow for interfacial debonding along the contact interface of the casing and cement based on bond strength, however physical characteristics for the microannulis region are not directly accounted for.

Carey et al. (2013) modeled elevated pore pressure via $\mathrm{CO}_{2}$ injection in computational simulations. These simulations were focused on damage and permeability increases from over-pressurization of the reservoir, including the propagation of damage along 
the wellbore annulus. A Mohr-Coulomb slip criterion is used to represent shear strength; excess shear stresses beyond the strength are assumed to result in damage which increases the material's permeability. Shear damage was assumed to increase the permeability of the wellbore cement from an initial intact value of $10^{-17} \mathrm{~m}^{2}$ to a maximum of $10^{-15} \mathrm{~m}^{2}$. For simulations with an overburden pressure $25 \mathrm{MPa}$ and formation confining stresses of $13 \mathrm{MPa}$, an over-pressurization of the injection reservoir of about $6 \mathrm{MPa}$ was sufficient to induce damage in the wellbore cement. The failure propagated along the wellbore and into the adjacent caprock in some simulations, and resulted in significant $\mathrm{CO}_{2}$ flow away from the reservoir. An important limitation of this study is that the permeability-stress relationship for the wellbore system was assumed and not based on measured values.

Schreppers (2015) studied the sealing properties of cement by analyzing the lifetime loading history a wellbore experiences from formation, cement and casing initialization, completion and operational phases, and cement-plugging and abandonment. This analysis includes transient thermal analysis during the drilling phase of the mud, hydrostatic slurry pressure, transient effects of cement shrinkage, formation pore pressure, and stress assumptions experienced by the cement, as well as other boundary conditions. Interface models between the steel casing and cement sheath, as well as the cement sheath and rock formation, are defined by interfacial elements. These elements are defined by a crack model and Coulomb friction model, where the interface fails by exceeding a tensile strength and shear stress along the interface respectively (Schreppers, 2015). This study did not estimate the permeability increases in response to predicted displacement or failure in the wellbore cement or along the cement-steel interface.

The models presented by Carey (2013), Schreppers (2015), and Gray (2009) present insight into stress conditions a wellbore system can experience and suggest possible failure modes that could affect the wellbore system's performance. However, these studies do not include an experimentally based model of wellbore microannulus permeability as a function of stress changes. In this paper, we present such a model.

This study describes measurements and subsequent modeling of the cement-casing microannulus. Measurements of flow through microannuli under varying confining pressures and internal casing pressures can be used to measure hydraulic aperture as a function of stress. These measurements are then used to fit a model for the compressibility and permeability of wellbore microannuli, which is implemented into a finite element simulation of the experimental set up.

\section{2: Methods and Materials}

\section{1: Experimental Set-up}

A mock-up of a wellbore system was used for lab-scale testing. The experimental configuration is shown in Figure 2. Specimens, consisting of a cement sheath cast on a 
steel casing with microannuli, are subjected to confining pressures and casing pressures in a pressure vessel that allows simultaneous measurement of gas flow along the axis of the specimen.

(a)

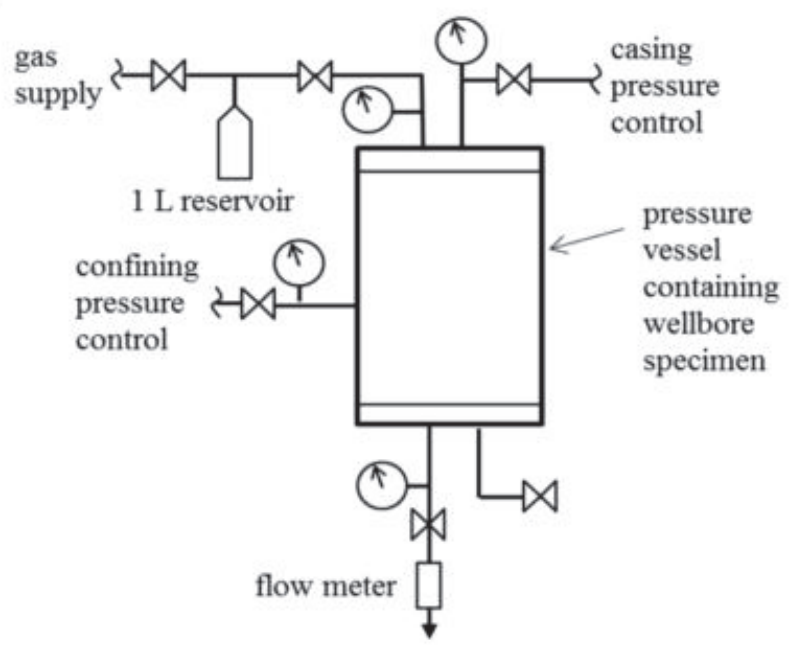

(b)

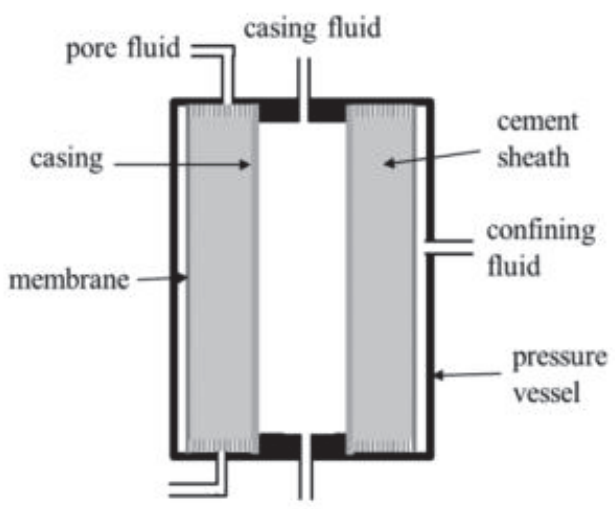

Figure 2: (a) Schematic of experimental configuration used to measure gas flow through cement-casing specimens under variable confining pressure and casing pressure. (b) Detail of specimen inside pressure vessel.

Test specimens were cast in a mold that included a central steel pipe. Class $\mathrm{G}$ cement was used (water/cement ratio of 0.33 ). The specimens were cured at $55^{\circ} \mathrm{C}$ in a humid environment for a minimum of 14 days prior to testing. The finished specimens have an outer diameter of $96 \mathrm{~mm}$, a casing inner diameter of $52.9 \mathrm{~mm}$, and a length of $200 \mathrm{~mm}$. The casing thickness varied from 1.5 to $3.2 \mathrm{~mm}$ between different specimens.

Prior to placement in the pressure vessel, flaws were induced in the specimens. "Large microannuli" of 136 microns were created by wrapping the casing in release film prior to casting the specimen. After 24 hours, the release film and casing were removed. The casing was then reinserted into cement sheath and the specimen was allowed to cure. After curing, the casing was loose enough to slide in and out of the cement sheath, illustrated in Figure 3. "Small microannuli" of 19 microns were created by cooling the interior of the casing of a cured specimen with liquid nitrogen or dry ice. In response to the cooling, the casing contracted sufficiently to de-bond with the cement. Once the temperature returned to ambient, the casing remained tight in the cement sheath and there were no visible cracks or damage in the cement. In some instances, an axial force was applied to the casing to ensure it was de-bonded. 


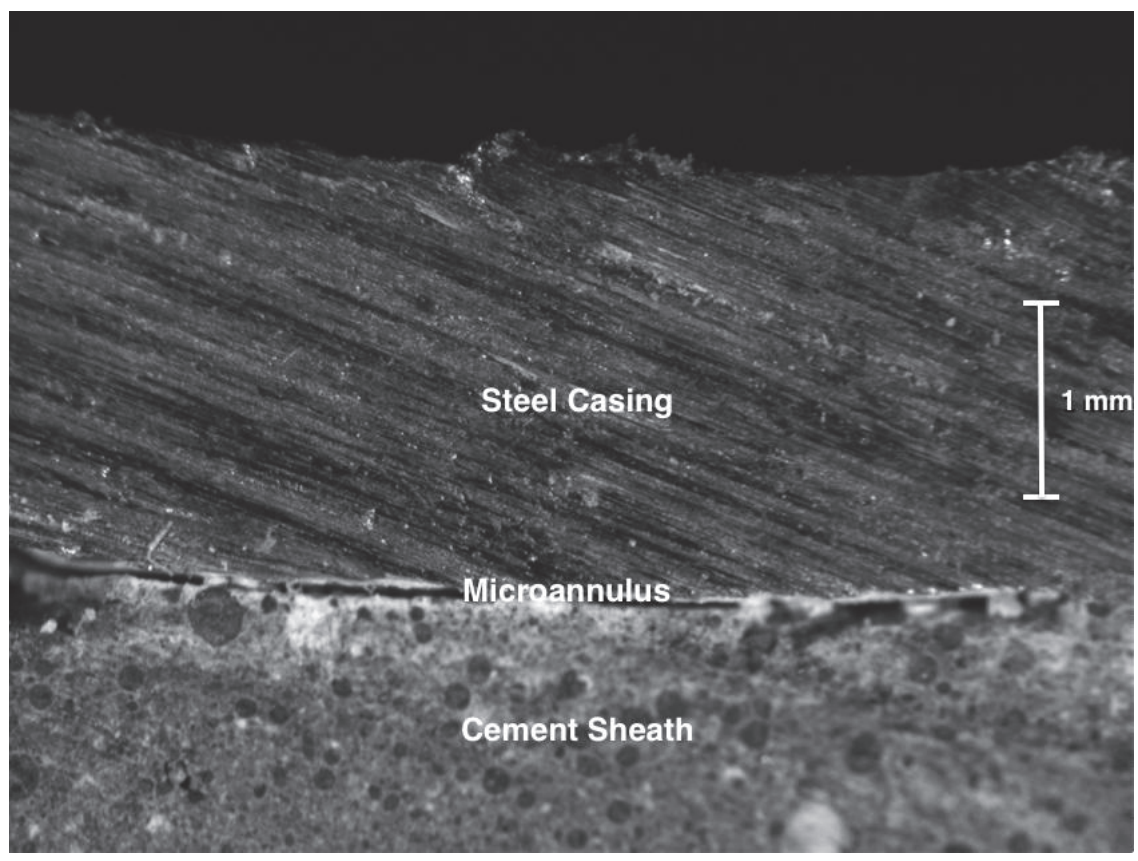

Figure 3: Photograph of microannulus at steel (above) and cement (below) contact.

The pressure vessel allows independent application of confining pressure to $35 \mathrm{MPa}$ and internal (casing) pressure to $20 \mathrm{MPa}$. The end pieces of the vessel include a steel boss that fits into the casing to isolate it. The end pieces also include ports that access the ends of the specimen for flow testing. Flow meters connect to the upstream and downstream ports on the permeameter pressure vessel system. The permeameter system can accommodate gas pressures to $15 \mathrm{MPa}$, and allows for both steady state and transient measurements to be made. Steady-state flow rates in the range of 0.1 to 10 $\mathrm{L} / \mathrm{min}$ are made with a flow meter. Steady-state flow rates between $0.001 \mathrm{~L} / \mathrm{min}$ and about $0.1 \mathrm{~L} / \mathrm{min}$ are made by monitoring the rate of pressure change in a $1 \mathrm{~L}$ reservoir. Measurements can be made with a backpressure greater than atmosphere. For lower flow rates, transient measurements are made using pulse decay methods.

The measured flowrates through the specimens with flaws were interpreted using the Forchheimer equation (Forchheimer, 1901), which includes both viscous (Darcy) and inertial (non-linear) flow terms. The Forchheimer equation can be expressed as

$-\frac{\nabla P}{Q}=\frac{\mu}{k A}+\frac{\beta \rho}{A^{2}} Q$

where $\nabla P$ is the gradient, $Q$ is the volumetric flowrate, $k$ is the permeability, $\beta$ is the inertial coefficient, $A$ is the cross sectional area involved in the flow, $\mu$ is viscosity, and $\rho$ is density. Plotting the left-hand side of Equation $1 \mathrm{vs}$. the flowrate yields a straight line with a slope that is a function of the inertial coefficient and an intercept proportional to permeability (Figure 4). In the absence of non-linear flow, the slope will be zero and Equation 1 reduces to Darcy's Law. 


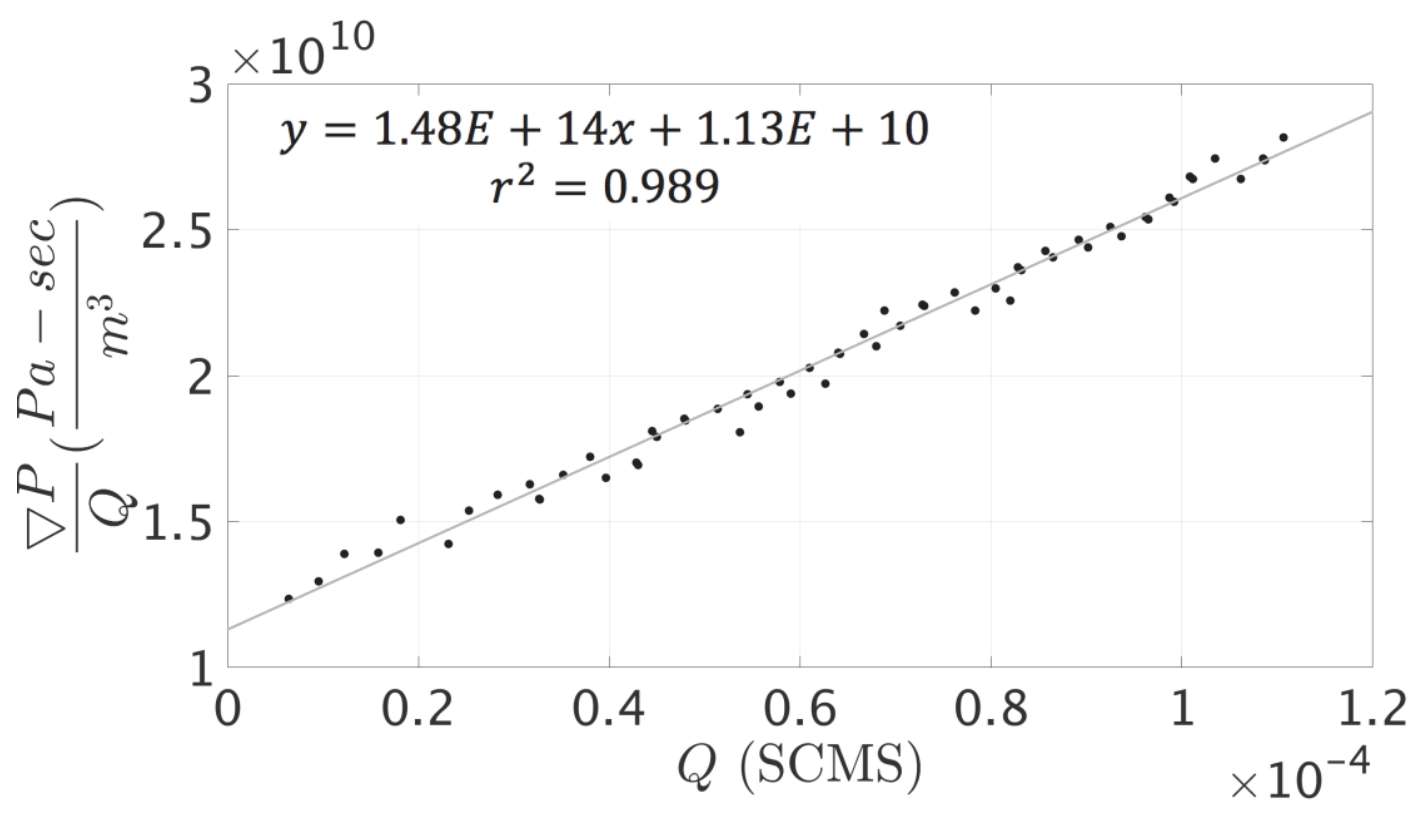

Figure 4: Experimental data fit to Equation 1 to decouple viscous and inertial flow components. The equation of the best linear fit to these data is used to estimate the permeability and the inertial coefficient.

The specimens featuring microannuli yielded flow rates that were more than 3 orders of magnitude greater than that for intact specimens (i.e., intact cement) under comparable conditions. Flow was therefore assumed to occur only through the flaws, and the calculated permeability was interpreted as a hydraulic aperture $(h)$ using the so-called cubic law (Witherspoon et al., 1980)

$h^{3}=\frac{12 k A}{w}$

where $w$ is the flaw width which for these tests is the outer circumference of the casing. In the tests reported here, the flow paths were sufficiently large that gas slip effects were not observed.

\section{2: Setup for Finite Element Model of the Wellbore}

Finite element models were created of the wellbore systems tested in the laboratory (as described in Section 2.1) in Sierra (see Appendix A2.1). The models include a cement sheath surrounding a steel casing; dimensions are consistent with the experimental system. The cement was modeled with the Kayenta plasticity model and the steel was assumed to behave elastically. Separate models were created to represent the interface between the cement and steel in different ways. A convergence study to determine the necessary number of elements used a full three dimensional model with a perfectly bonded interface between the steel and cement. Results from this model were compared to an analytical solution for an elastic bi-material hollow cylinder. 
Subsequent three-dimensional quarter-symmetric models were created using the same meshing technique, but included additional elements to explicitly represent the microannulus at the interface between the steel casing and cement sheath. The microannulus elements could be assigned as open (gap) or as a separate microannulus material. Dimensions of the two models of the laboratory wellbore configuration are illustrated by Figure 5 and Table 1. In this study the microannulus region was defined with the Kayenta constitutive model.

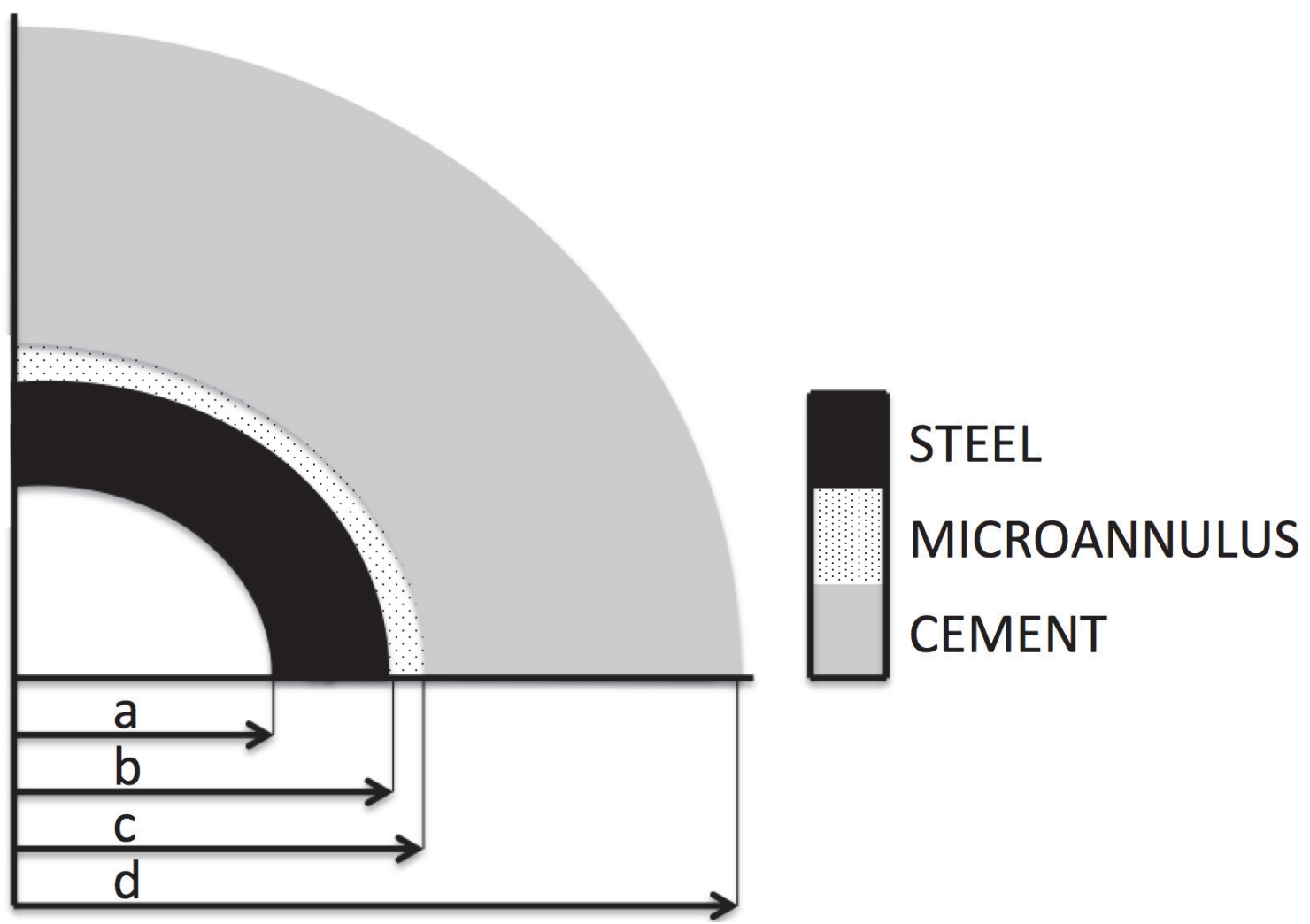

Figure 5: An exploded view of the laboratory wellbore model used for the parametric study. Dimensions for model utilizing this configuration are shown in Table 2. 
Table 1: Laboratory wellbore radial dimensions $(\mathrm{mm})$ shown for a $2.35 \mathrm{~mm}$ casing with a small and large microannulus and tags referencing Figure 5.

\begin{tabular}{|c|c|c|c|}
\hline Location & Tag & $\begin{array}{c}\text { Small } \\
\text { Microannulus } \\
\left(\mathbf{1 9} \boldsymbol{\mu}_{\mathbf{m}}\right)\end{array}$ & $\begin{array}{c}\text { Large } \\
\text { Microannulus } \\
\left(\mathbf{1 3 6} \boldsymbol{\mu}_{\mathbf{m}}\right)\end{array}$ \\
\hline Internal Steel Casing & $\mathrm{a}$ & $\mathbf{2 6 . 4 7 5}$ & $\mathbf{2 6 . 4 7 5}$ \\
\hline $\begin{array}{c}\text { External Steel } \\
\text { Casing/ Internal } \\
\text { Microannulus }\end{array}$ & $\mathrm{b}$ & 28.825 & 28.825 \\
\hline $\begin{array}{c}\text { External } \\
\text { Microannulus/ } \\
\text { Internal Cement } \\
\text { Sheath }\end{array}$ & $\mathrm{c}$ & 28.844 & 28.961 \\
\hline $\begin{array}{c}\text { Outer Cement } \\
\text { Sheath }\end{array}$ & $\mathrm{d}$ & 50.8 & 50.8 \\
\hline
\end{tabular}

\subsection{1: Material Parameters}

The properties used for the modeling of the elastic laboratory wellbore systems are given in Table 2.

Table 2: Laboratory wellbore elastic properties used in numerical convergence simulations.

\begin{tabular}{|c|c|c|c|}
\hline Parameter & Symbol & Unit & Value \\
\hline Young's Modulus: Cement & $E_{C}$ & $\mathrm{~Pa}$ & $4.00 \times 10^{9}$ \\
\hline Young's Modulus: Steel & $E_{S}$ & $\mathrm{~Pa}$ & $2.00 \times 10^{11}$ \\
\hline Poisson's Ratio: Cement & $v_{C}$ & Dimensionless & 0.19 \\
\hline Poisson's Ratio: Steel & $v_{S}$ & Dimensionless & 0.30 \\
\hline
\end{tabular}

\subsection{2: Loading and Boundary Conditions}

Boundary conditions included the externally applied confining pressure and the internal casing pressure. These pressures were applied at a linear ramp rate over a short period of pseudo-time, starting at a zero pressure state and increasing to the desired internal and/or external pressure load. Because the model response is time-independent, intermediate boundary conditions can be interpolated from these conditions; i.e. over a 0.5 second simulation with a desired internal and external pressure of $20 \mathrm{MPa}$ and 30 $\mathrm{MPa}$ respectively, the state of pressure at 0.25 seconds can be inferred at $10 \mathrm{MPa}$ and $15 \mathrm{MPa}$ respectively. The loading rate applied to the FEA implementation of the laboratory wellbore was modeled with implicit quasi-static capabilities and therefore it was not intended to simulate the loading rate in the laboratory. 


\subsection{3: Wellbore model with microannulus}

Stiffness elements (i.e. interfacial elements) are assigned to the microannulus regions, which are intended to capture the change in aperture of the microannulus as a function of normal stress across the microannulus using the joint stiffness model of Bandis et al (1983). These elements are shown as the region of annular joint spacing in Figure 6. Interfacial elements span the circumference between the steel casing (red) and cement sheath (yellow), where a local coordinate system $\left(x^{\prime}, y^{\prime}, z^{\prime}\right)$ belonging to the Kayenta material model defines a unique orthogonal system for each interfacial block; including a normal joint direction, orientation along the joint, and direction perpendicular to both of these. These joint directions are obtained from translations on the $x, y$, and $z$ coordinates, respectively. This method was used to calculate unique normal directions for joints spanning along the circumference of the microannulus region

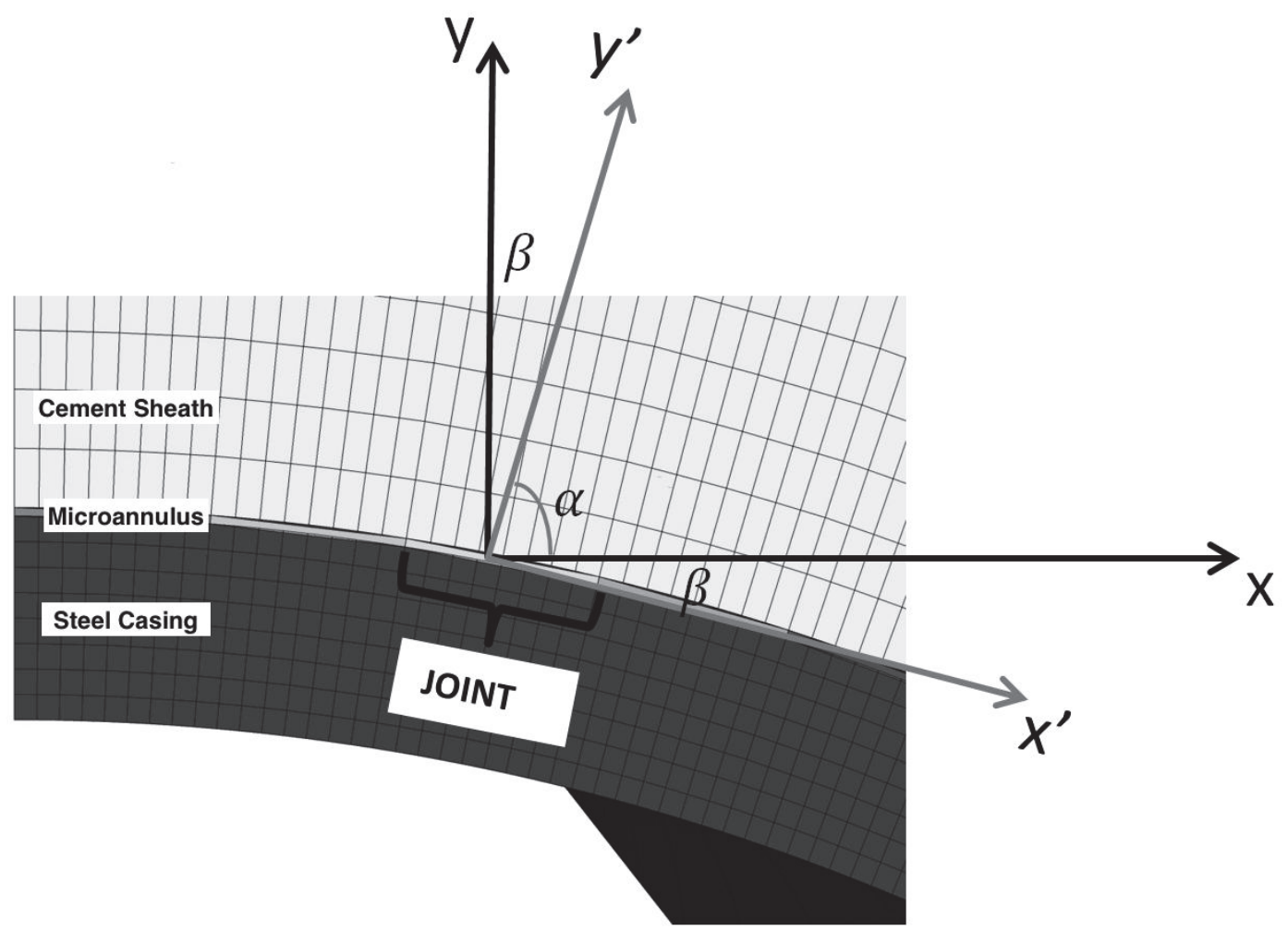

Figure 6: Coordinate systems used to determine stress acting across curved surface of microannulus joint. 


\section{3: Results}

\section{1: Experimental Results}

Hydraulic aperture as a function of confining pressure for a specimen with a large microannulus is shown in Figure 7. The initial hydraulic aperture was 100 microns at a confining pressure of $4 \mathrm{MPa}$. With increasing confining pressure, the hydraulic aperture decreases non-linearly with increasing rate of confinement, averaging at a rate of approximately 4 micron per $\mathrm{MPa}$, until a confining pressure of $20 \mathrm{MPa}$ is reached. With continued increase in confining pressure above $20 \mathrm{MPa}$, the aperture decreases only slightly.

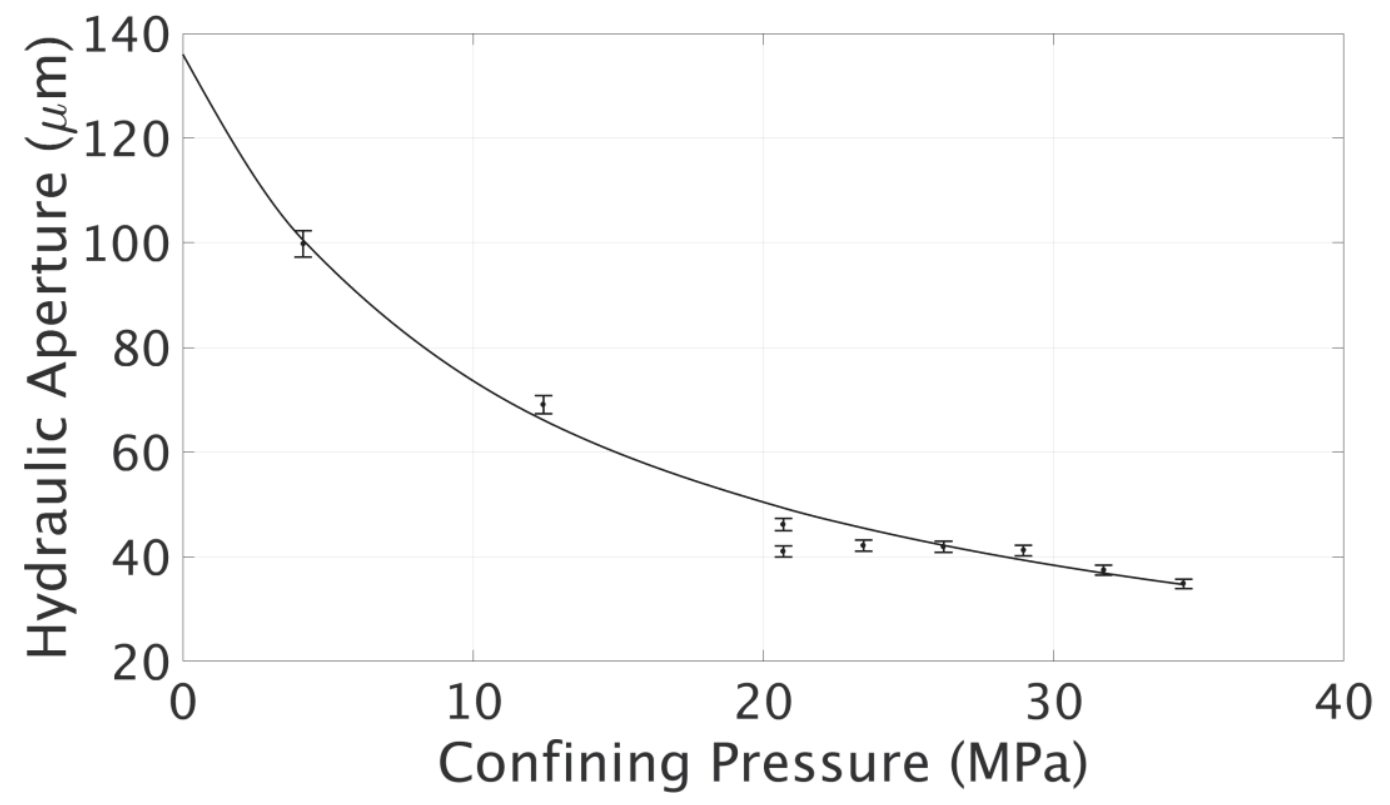

Figure 7: Hydraulic aperture as a function of confining pressure for specimen with large microannulus. The line is the best fit line to the hyperbolic model for these data $(5 \%$ experimental error bars are shown for laboratory measured data).

In Figure 8, hydraulic apertures as a function of confining pressure for specimens with small microannuli are shown. With increasing confining pressure, the hydraulic aperture decreases. These hydraulic apertures are about one order of magnitude smaller than that for the specimens with a large microannulus. 


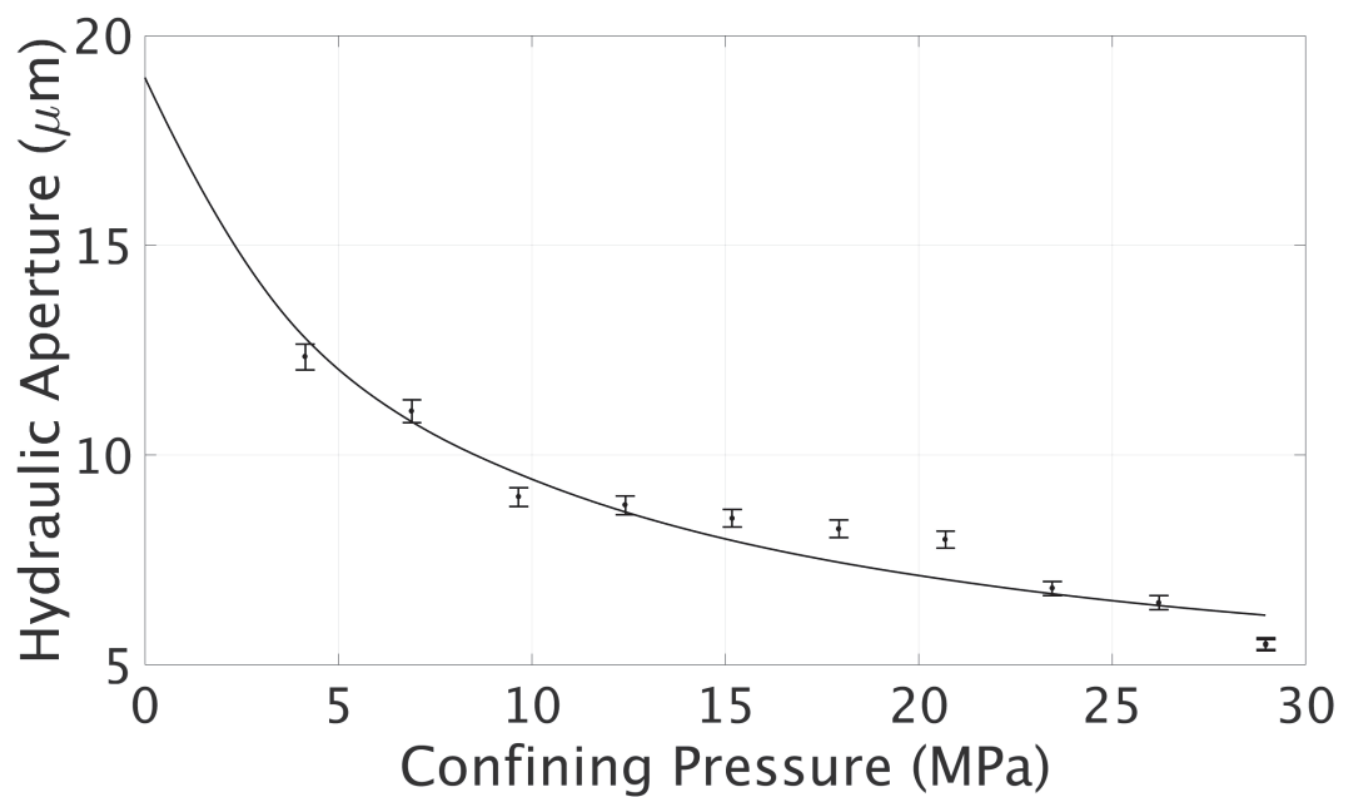

Figure 8: Hydraulic aperture as a function of confining pressure for specimens with small microannuli. The line is the best fit to the hyperbolic model for these data $(5 \%$ experimental error bars are shown for laboratory measured data).

\section{2: Fitting Laboratory Data to Model}

The hydraulic aperture change with applied stress data given in Figures 7 and 8 are used to parameterize the hyperbolic model (see Appendix 1) for a large and small microannulus. The hyperbolic model can be given in the linear form (Bandis et al., 1983)

$\frac{\Delta V_{j}}{\sigma_{n}}=a-b \Delta V_{j}$

where $\frac{1}{a}=K_{n i}, \frac{a}{b}=V_{m}$ or the maximum closure, and $\Delta V_{j}$ is the closure of a joint under $\sigma_{n}$. Plotting $\frac{\Delta V}{\sigma_{n}}$ vs. $\Delta \mathrm{V}$ yields a straight line with an intercept of $a$ and a slope of $-b$. The hydraulic aperture data were interpreted as closure by subtracting the current aperture from the previous aperture. Because the test was conducted by controlling the confining pressure, the model is given in terms of confining pressure and not normal stress across the interface. In Figures 9 and 10, the best fit straight line to Equation 3 is given for the experimental data measured for the large aperture and small aperture microannuli. Initial apertures (with no confining pressure) for both data sets were found by extrapolating the model response to zero normal stress; these apertures were $136 \mu \mathrm{m}$ and $19 \mu \mathrm{m}$ for the large and small microannuli, respectively. 


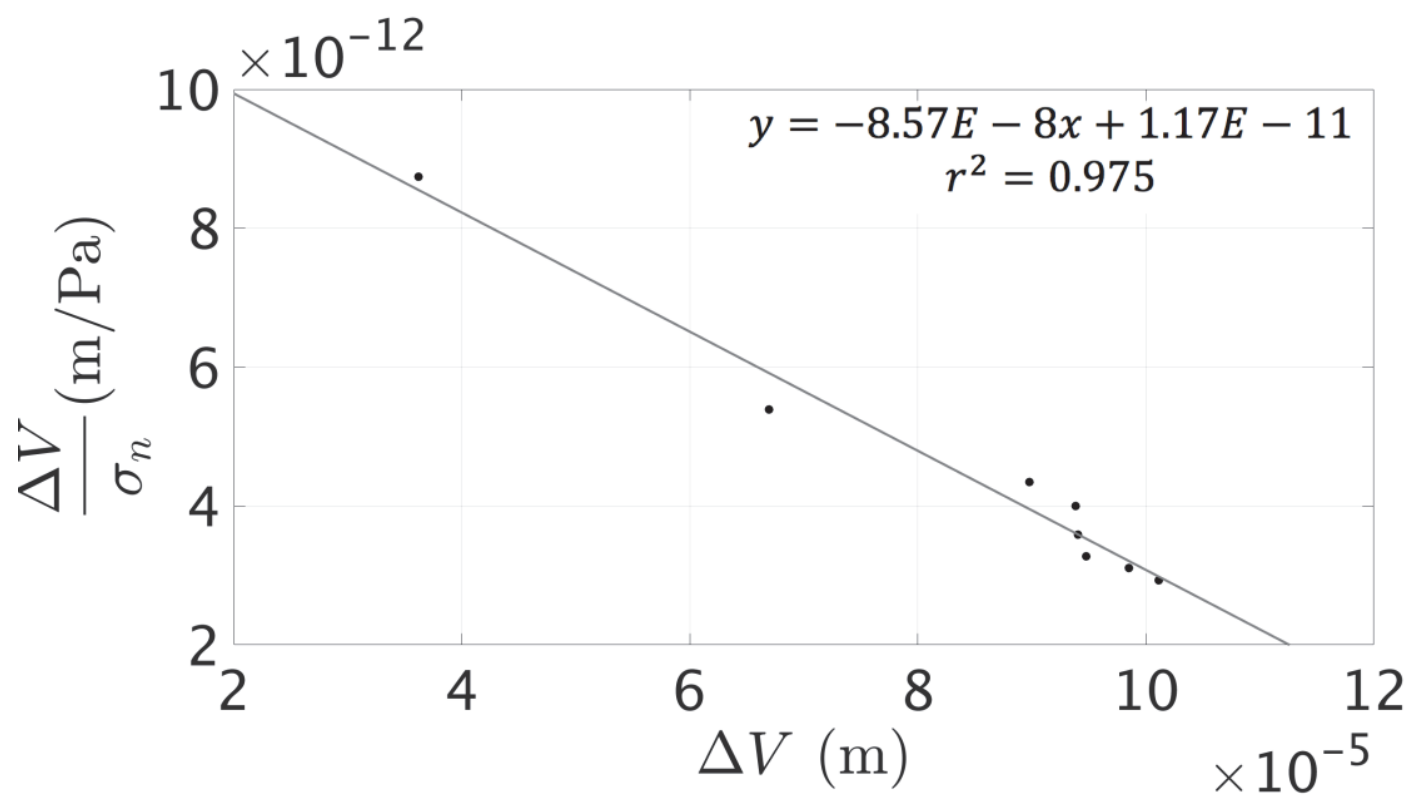

Figure 9: Fitting of laboratory data from large microannulus to hyperbolic model.

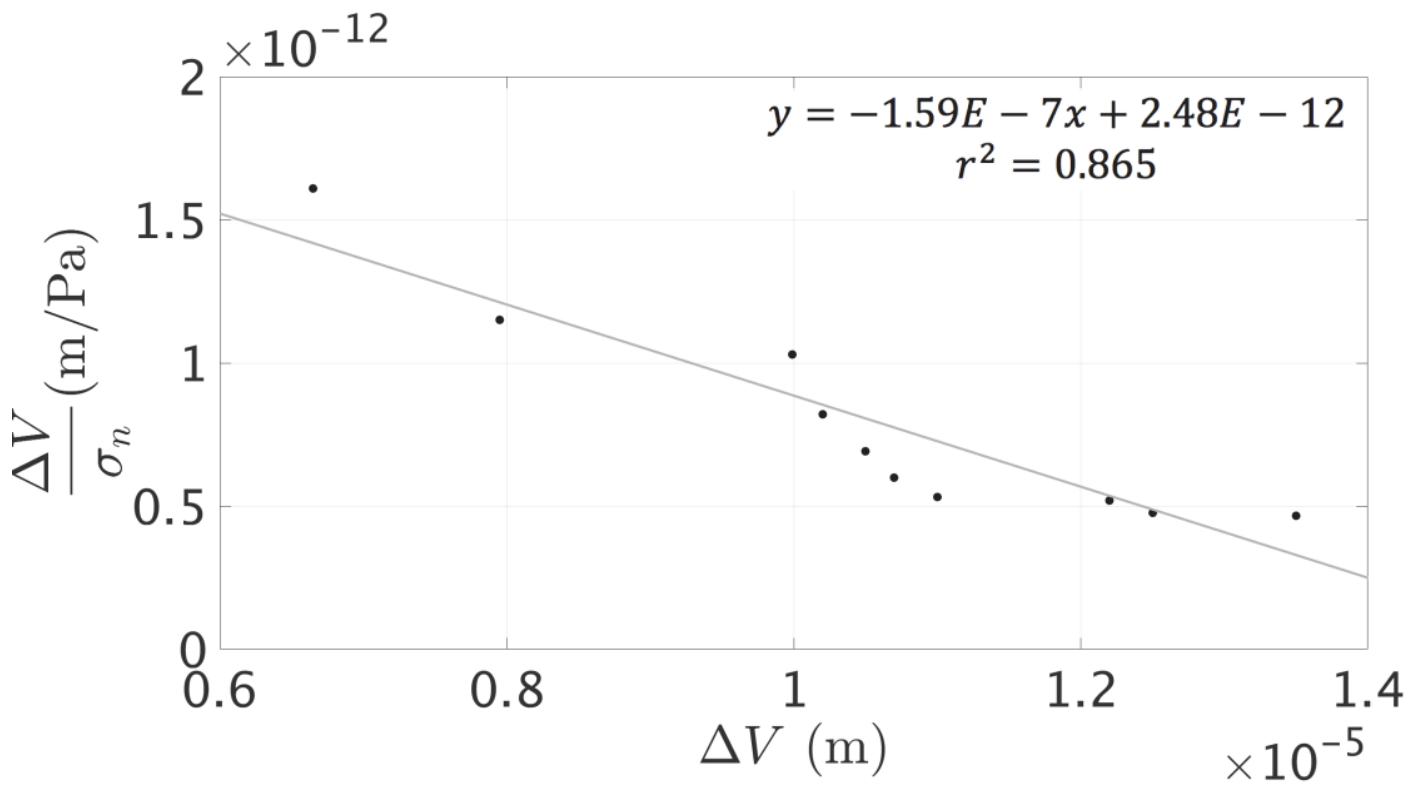

Figure 10: Fitting of laboratory data from small microannulus to hyperbolic model.

Using the parameters derived from fitting the data to the hyperbolic model, the prediction for hydraulic aperture as a function of confining pressure is given in Figure 7 and 8 . These results suggest that the hyperbolic model provides a reasonable representation of the measured microannulus response to confining pressure. The hyperbolic model is subsequently implemented in finite element modeling of wellbore 
system to describe the stress-dependent change in the hydraulic aperture and consequently permeability of a wellbore microannulus.

The joint parameters derived from laboratory tests were used to populate the numerical model of the microannulus. Figures 11 and 12 compare the laboratory data for the large $(136 \mu \mathrm{m})$ and small $(19 \mu \mathrm{m})$ microannuli with the numerical results, respectively. Both microannulus sizes were analyzed with the cement sheath parameterized with a Kayenta constitutive model. The modeled microannulus is shown to be slightly stiffer than the laboratory measured values in the $136 \mu \mathrm{m}$ microannulus model. It is hypothesized that the occurrence of the large microannulus showing increased stiffness with respect to the small microannulus is due to furthered discontinuity between the cement and steel interface. That is, it is assumed that the microannulus is in contact throughout the circumference of the laboratory wellbore during FE computations; missing elements, voids or spaces of non-contact were not accounted for in this simulation.

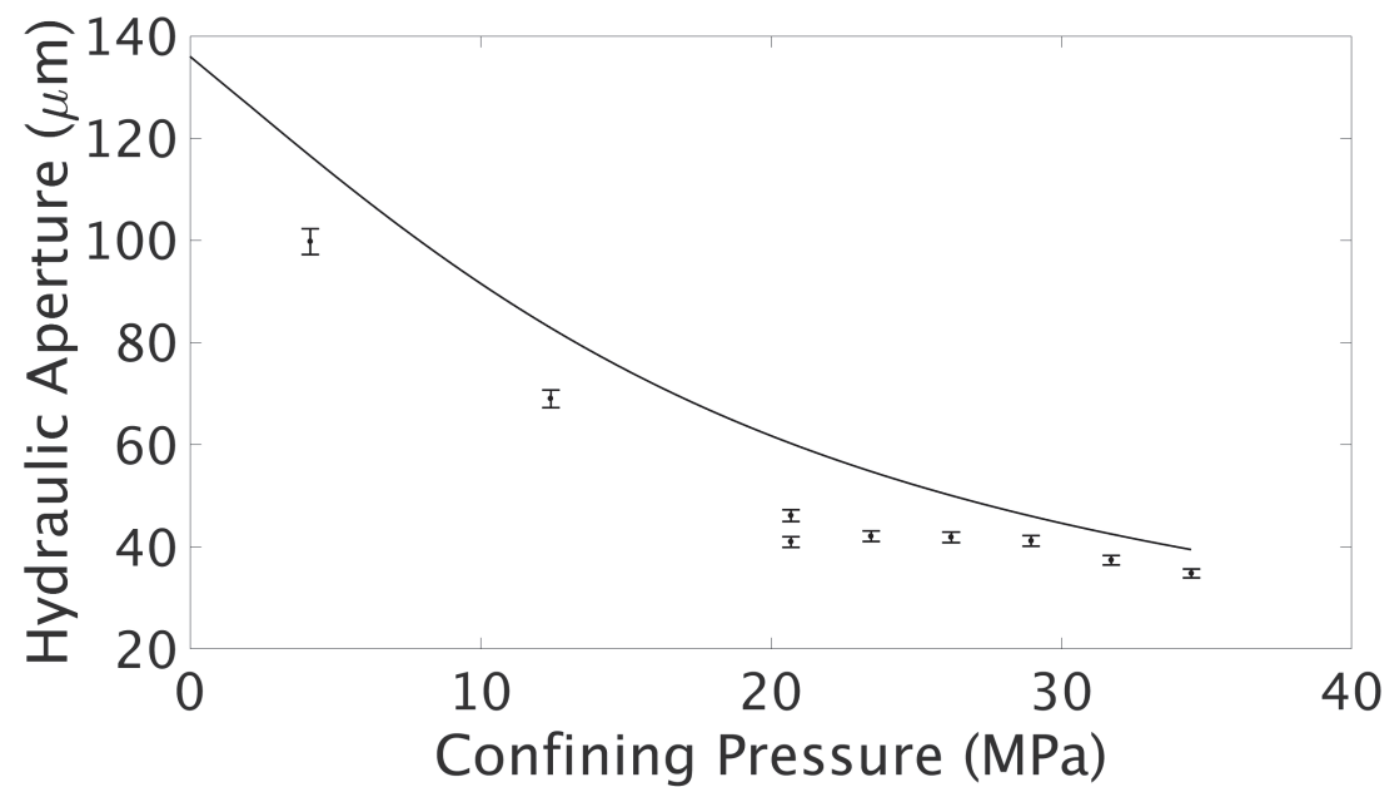

Figure 11: Laboratory measurements and numerical model comparison for the $136 \mu \mathrm{m}$ microannulus joint ( $5 \%$ experimental error bars are shown for laboratory measured data). 


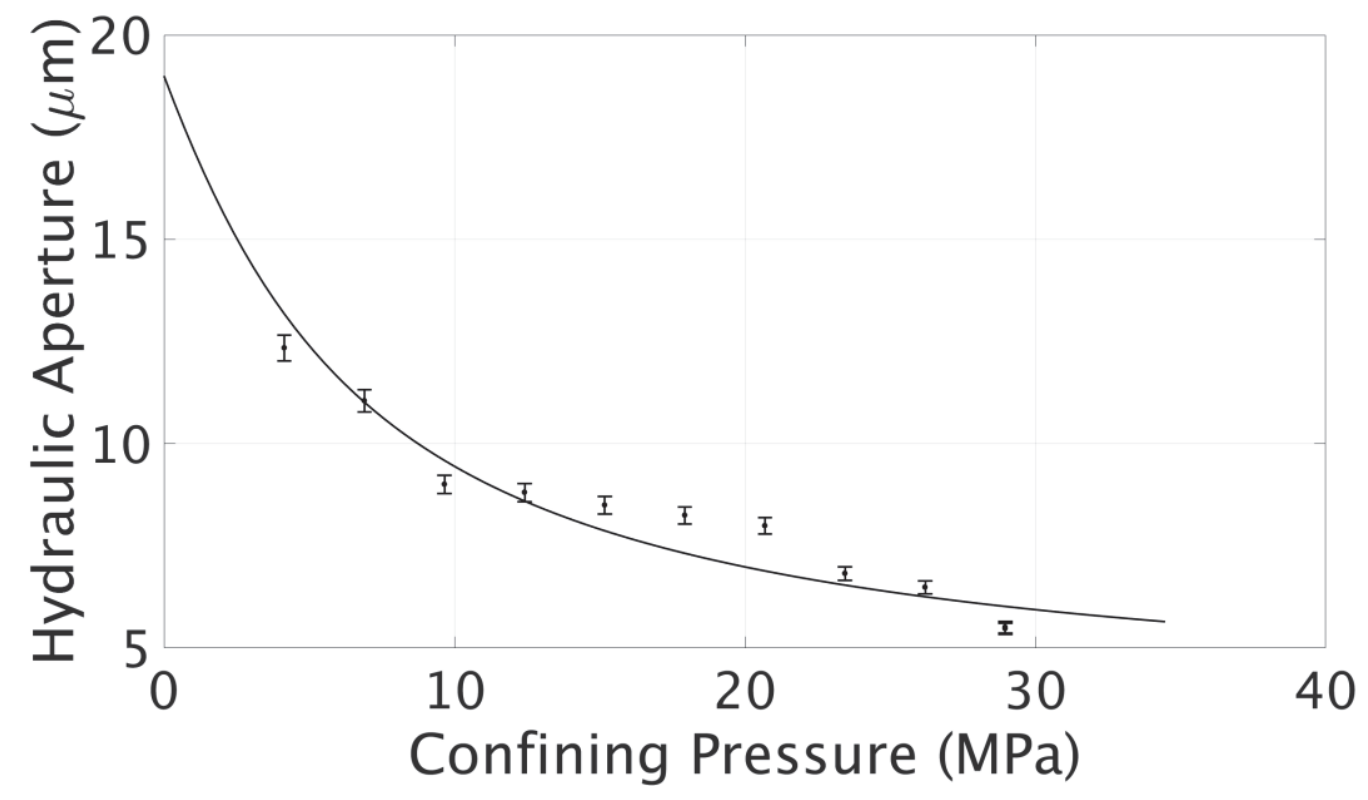

Figure 12: Laboratory measurements and numerical model comparison for the $19 \mu \mathrm{m}$ microannulus joint ( $5 \%$ experimental error bars are shown for laboratory measured data).

\section{4: Discussion}

With this model, the size (thickness over cross sectional area) of the microannulus is equivalent to the hydraulic aperture. Thus, the permeability of the microannulus can be back-calculated using Equation 2. Figure 13 shows the permeability of the microannuli as a function of confining pressure. The permeability decreases as confining pressures are applied. For the larger microannulus, the permeability decreases from an initial permeability of $3.2 \times 10^{-13} \mathrm{~m}^{2}$ to $7.8 \times 10^{-15} \mathrm{~m}^{2}$ as the confining pressure is increased to 34 $\mathrm{MPa}$; for the smaller microannulus, the permeability increases from $6.8 \times 10^{-16} \mathrm{~m}^{2}$ to $1.8 \times 10^{-17} \mathrm{~m}^{2}$ for this same increase in confining pressure. The permeability of intact cement is approximately $1 \times 10^{-18} \mathrm{~m}^{2}$ (Bear, 2013). Therefore, even with confining pressures of $34 \mathrm{MPa}$, an unrepaired wellbore microannulus can exhibit permeability approximately one to two orders of magnitude higher than that of intact cement and thus serve as a significant leakage pathway. 


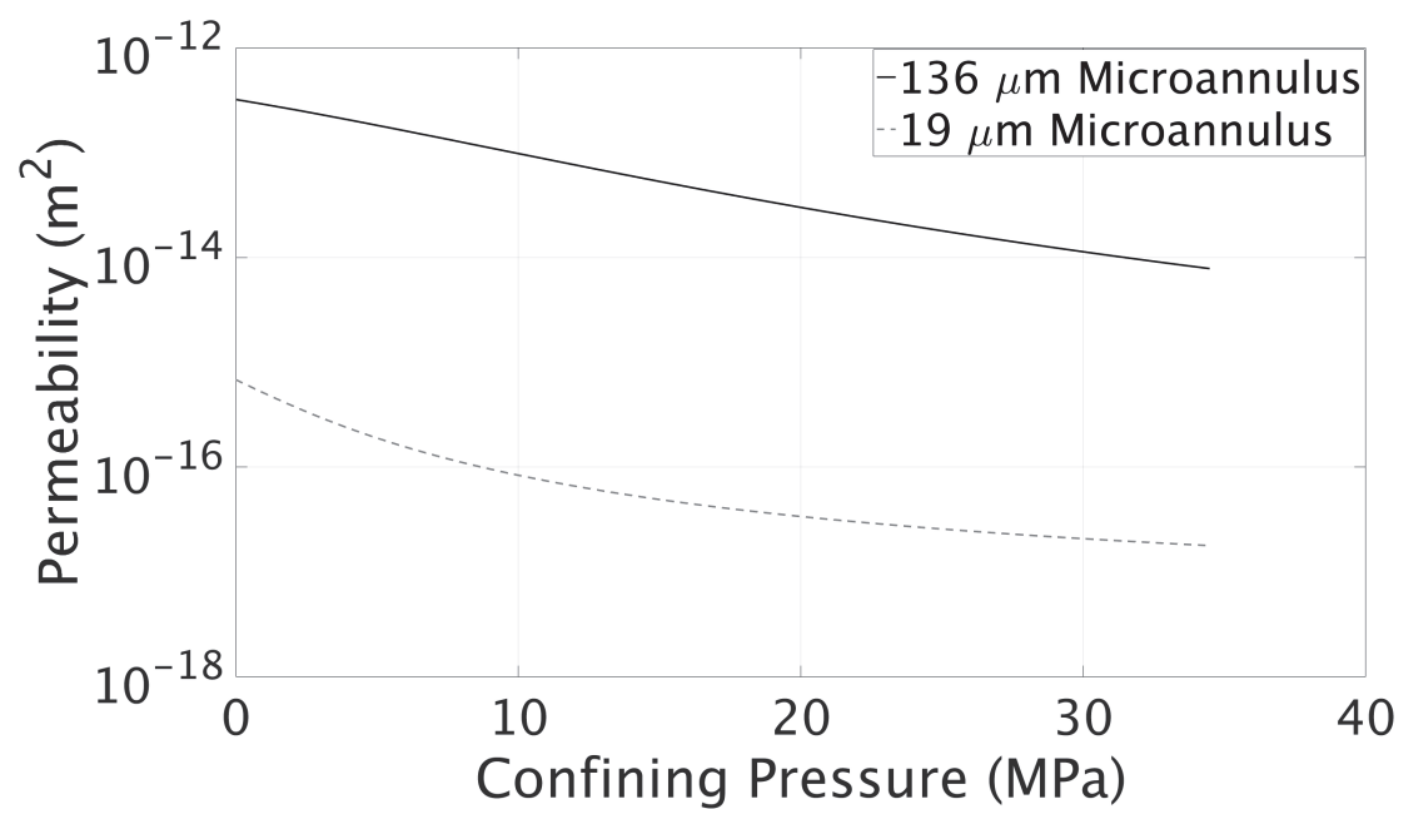

Figure 13: $136 \mu \mathrm{m}$ and $19 \mu \mathrm{m}$ microannulus permeability shown upon increasing confinement pressure.

Joint parameterization using laboratory data assumed that the joint normal stress is equivalent to the confining pressure, while numerical simulations used the stress normal to the microannulus element. In Figure 14, the applied confining pressure and the calculated contact normal stress across the face of the microannulus is given. For both microannuli, the contact stress is reasonably close to the confining pressure. For the larger and less stiff microannulus, this relationship is less linear. 


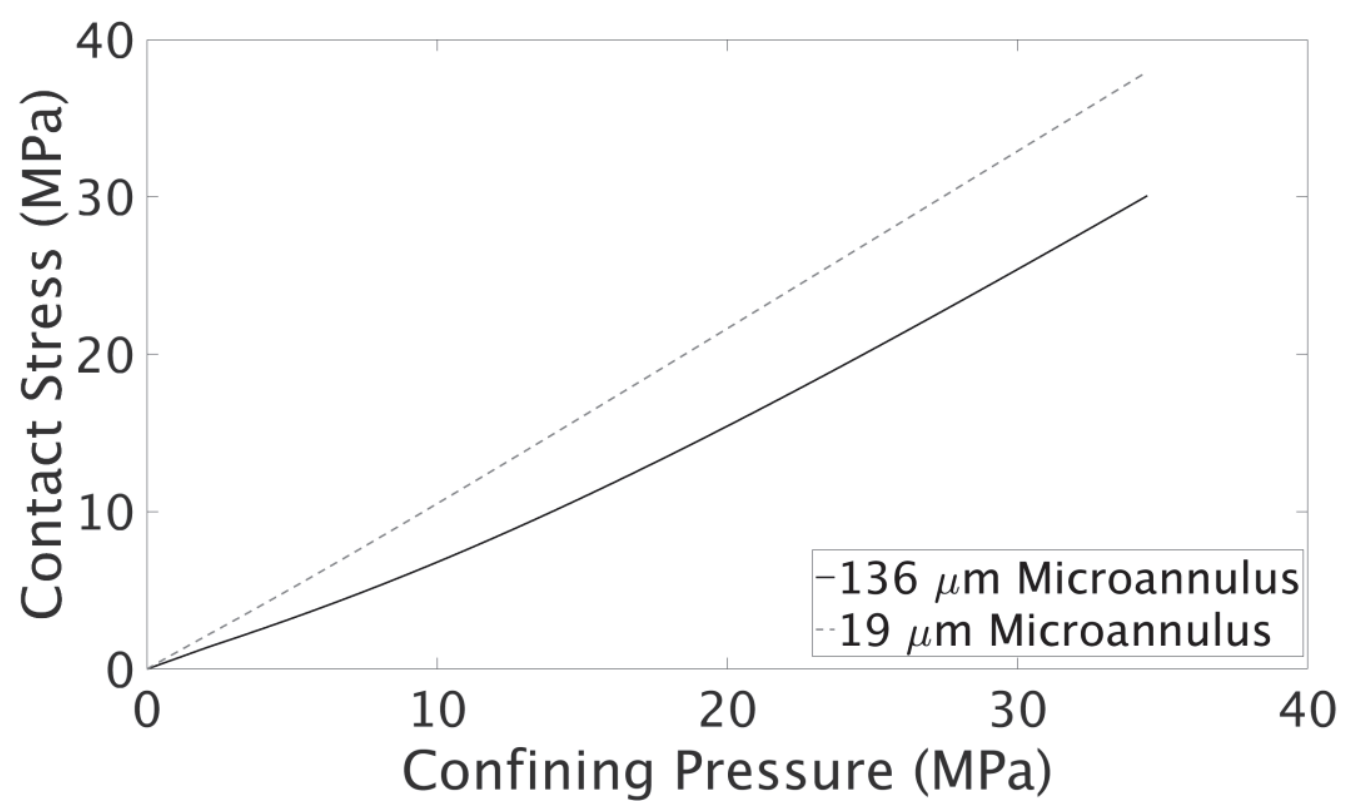

Figure 14: $136 \mu \mathrm{m}$ and $19 \mu \mathrm{m}$ microannulus joint contact stress and confinement pressure relationship.

The "cubic law" presented in Equation 2 is used to estimate the hydraulic aperture, which in turn was assumed to be equivalent to the mechanical aperture. Under high flow rates and large apertures, it is a reasonable assumption that the mechanical and hydraulic aperture are equivalent. However, this assumption becomes less certain when fracture aperture approaches the scale of the surface roughness (Iwai, 1976; Renshaw, 1995). In this study, the surface roughness between the steel casing and cement sheath was accounted for by adjusting the stiffness based on the model of Bandis et al. (1983), thereby the microannulus roughness features are embedded into the model description. However, by accounting for the surface roughness as a fitting coefficient, it is possible that a more accurate representation of hydraulic aperture closure may be developed. Explicitly incorporating the surface roughness in a model of microannulus behavior would require characterizing and parameterizing the surface roughness, which was not available for these experiments.

The joint aperture response during loading and unloading can be different (Souley et al., 1995). Similarly, the hydraulic apertures interpreted from measurements on microannuli have indicated that the response may be hysteretic: hydraulic aperture changes during unloading were sometimes smaller than those during loading (Stormont et al., 2015). However, the constitutive model implemented for the microannulus does not have history dependent properties. A more complete model for microannulus behavior would include hysteresis.

The numerical model was applied to test conditions different from those used to derive the microannulus model parameters. Figure 15 shows the measured and predicted 
response of the $136 \mu \mathrm{m}$ microannulus with a constant confining pressure of $13.78 \mathrm{MPa}$ with an increasing internal casing pressure. The predicted response is less stiff than that measured. This result may be a consequence of hysteresis or plastic hardening of the microannulus; the measurements were made after the sample had been unloaded from greater confining pressures, and thus microannulus has been effectively hardened. In contrast, the microannulus model was parameterized from data obtained during initial loading only.

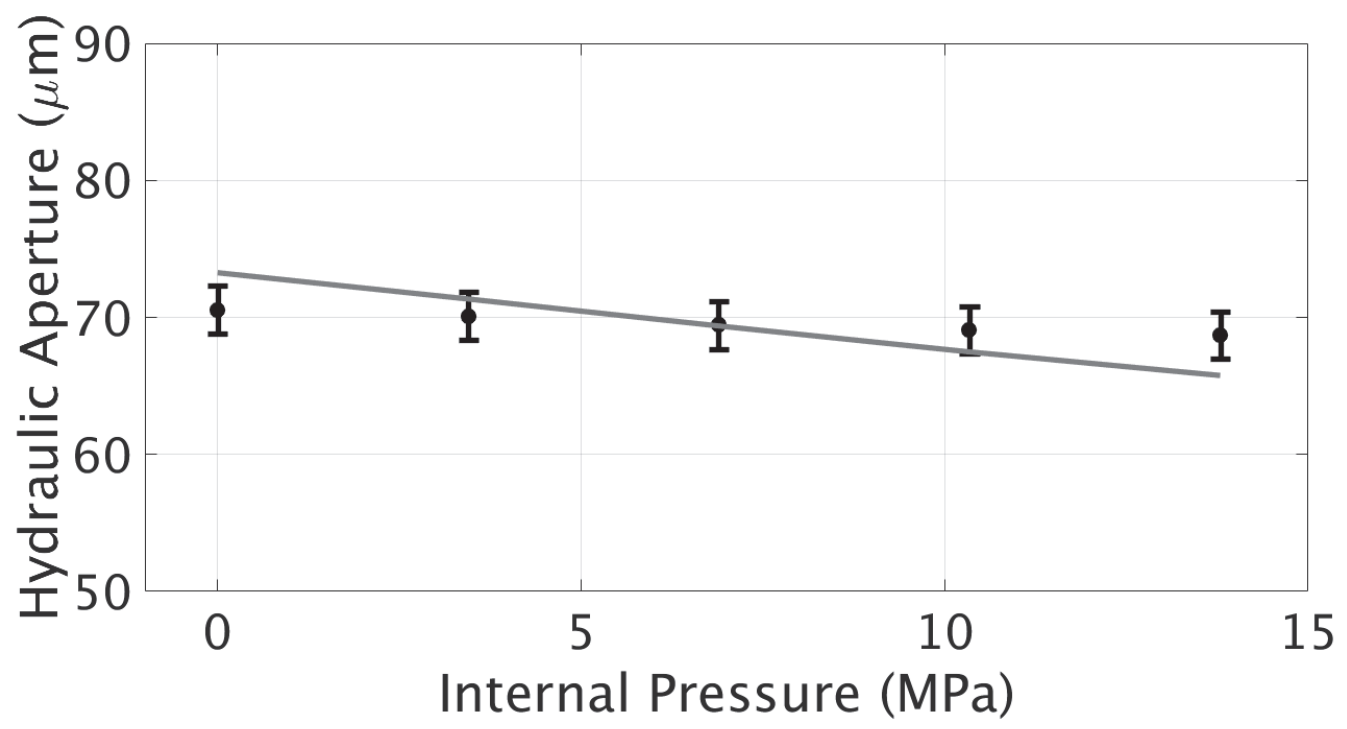

Figure 15: Laboratory measurements and numerical model comparison for the $136 \mu \mathrm{m}$ microannulus joint as a function of internal casing pressure (5\% experimental error bars are shown for laboratory measured data). The confining pressure was constant at 13.78 MPa.

The numerical implementation for the microannulus behaves in response to normal joint behavior in a hyperbolic manner as discussed by Bandis et al. (1983). Other relationships may fit these data as well. Future studies should also consider the joint response to shear loading in addition to normal loading such as that given by Souley et al. (1995).

The model was developed based on laboratory measurements that were made under uniform confining stresses, yet application of the model to field conditions may include anisotropic stress conditions. We hypothesize that an anisotropic stress field would result in the greatest microannulus closure in the maximum principal stress direction, and consequently, a non-uniform flow field through the microannulus would develop. 


\section{5: Conclusions}

Laboratory tests measured the compressibility and flow characteristics of wellbore microannuli. Specimens, consisting of a cement sheath cast on a steel casing with microannuli, were subjected to confining pressures and casing pressures in a pressure vessel that allows simultaneous measurement of gas flow along the axis of the specimen. The flow was interpreted as the hydraulic aperture of the microannuli. We found the hydraulic aperture decreases as confining stress is increased. The larger the initial hydraulic aperture, the more it decreases as confining stress increases. The changes in measured hydraulic aperture correspond to changes of many orders of magnitude in permeability of the wellbore system, suggesting that microannulus response to stress changes may have a significant impact on estimates of wellbore leakage.

The experimental data were satisfactorily described by the hyperbolic model of Bandis et al. (1983) which had been previously developed for closure of rock joints and fractures. The model is parameterized with two terms, one for the initial stiffness of the microannulus and one for the maximum aperture closure. With this model, we can estimate the hydraulic aperture, and therefore permeability, as a function of the stress acting across the microannulus.

A finite element model of a wellbore system was developed that included elements representing the microannulus that incorporated the hyperbolic joint model. The thickness of the microannulus elements is equivalent to the hydraulic aperture. The calculated normal stress across the microannulus used in the numerical implementation was found to be similar to the applied confining pressure in the laboratory tests. The microannulus elements were found to reasonably reproduce laboratory behavior during loading from confining pressure increases. The calculated microannulus response to internal casing pressure changes was less stiff than measured, which may be due to hardening of the microannulus during testing.

We found that the Bandis et al. (1983) joint closure model satisfactorily describes microannulus response, and therefore can be incorporated into models of damaged wellbore systems to estimate the response to different conditions that may be of interest to particular applications where wellbore integrity is of interest. In particular, the microannulus model could be used to estimate $\mathrm{CO} 2$ leakage as a function of formation stress changes and/or displacements, or loading from casing expansion or contraction during wellbore operations. Recommendations for future work include an application of the joint model with a thermally active large-scale reservoir coupled with pore pressure caused by dynamic $\mathrm{CO}_{2}$ injection and subsequent microannulus region affects. Future work should also consider the role of hysteresis and shear loading on the joint response. 


\section{ACKNOWLEDGEMENTS}

We thank the anonymous reviewers for their constructive feedback. We also would like to thank Chris Jones of Sandia National Laboratories for his careful review of the work. The contributions of all reviewers have greatly improved the communication of results. This material is based upon work supported by the U.S. Department of Energy (DOE) National Energy Technology Laboratory (NETL) under Grant Number DEFE0009562. Sandia National Laboratories is a multi-program laboratory managed and operated by Sandia Corporation, a wholly owned subsidiary of Lockheed Martin Corporation, for the U.S. Department of Energy's National Nuclear Security Administration under contract DE-AC04-94AL85000. SAND2016-4456 J. 


\section{Appendix 1: Model of Microannulus Closure}

As the wellbore microannulus resembles the opening of a mode 1 fracture, its permeability can be related to the fracture aperture. The size of an aperture depends upon the stresses that are acting to close or open it and these stresses are affected by the contact of asperities on the fracture surface; the general behavior of a fracture under normal stress exhibits a non-linear response.

Bandis et al. (1983) describe a hyperbolic relationship that relates joint opening, or change in aperture, to the state of stress as illustrated in Figure A.1 and given by Equation A.1:

$\sigma_{n}=\frac{u_{n} K_{n i} V_{m}}{V_{m}-u_{n}}$

where $\sigma_{\mathrm{n}}$ is the normal stress, $\mathrm{u}_{\mathrm{n}}$ is the normal joint displacement, $\mathrm{V}_{\mathrm{m}}$ is the maximum joint closure and the initial joint normal stiffness is represented as $\mathrm{K}_{n i}$, illustrated in Figure A.1. This equation can equivalently be expressed in terms of $u_{n}$ by:

$u_{n}=\frac{V_{m} \sigma_{n}}{V_{m} K_{n i}+\sigma_{n}}$

The tangent of $\sigma_{n}$ vs. $u_{n}$ yields a hyperbolic relationship for the joint tangent normal stiffness shown in Equation A.3.

$K_{n}=K_{n i}\left(1-\frac{\sigma_{n}}{K_{n i} V_{m}}\right)^{2}$

The hyperbolic model, shown schematically in Figure A.1, has been shown to provide a reasonable description of rock and fractured joint deformation (Bandis et al., 1983; Souley et al., 1995; Martinez et al., 2013); here, we use this model to describe the aperture of the microannulus as a function of stress. The aperture, in turn, can then be used with the cubic law (subsequently discussed) to predict the permeability of the microannulus. 


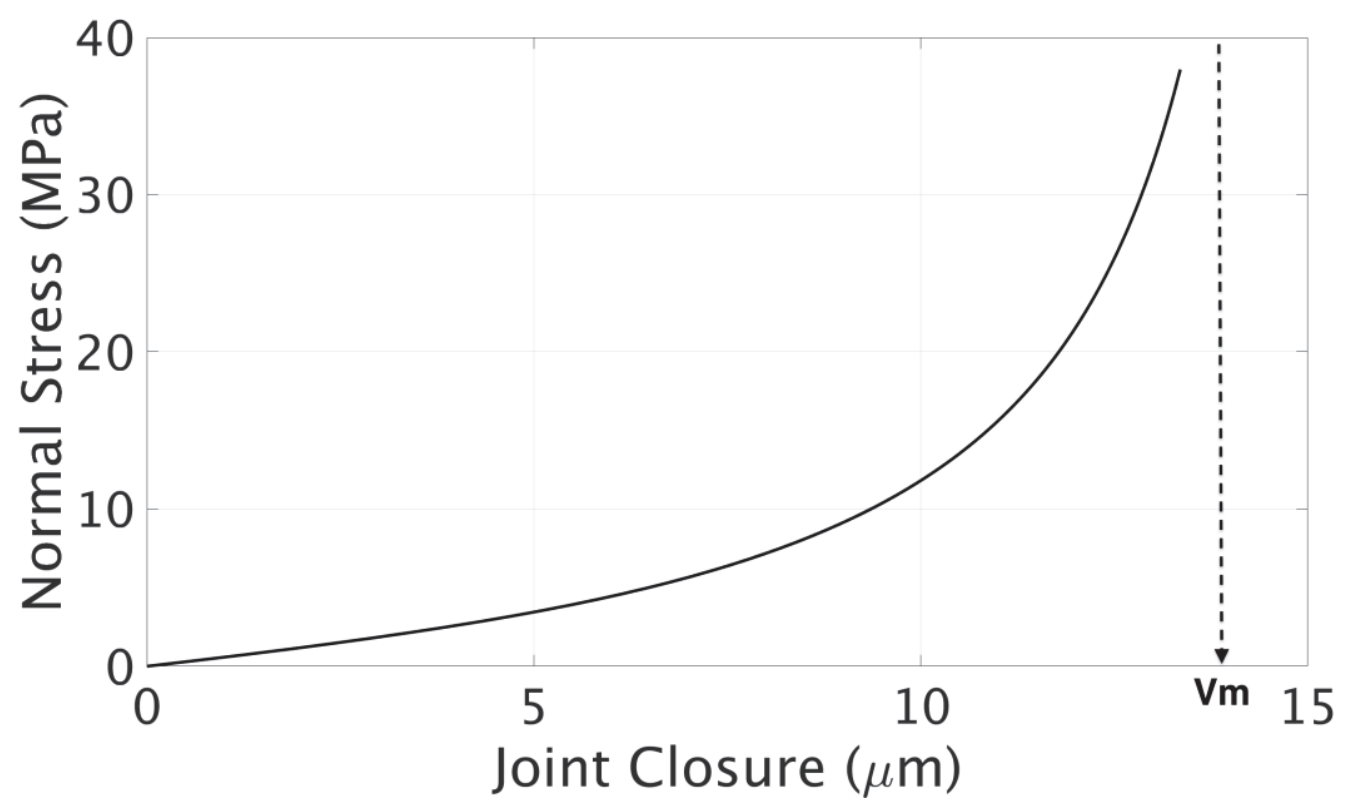

Figure A.1: Joint closure and normal stress relationship of hyperbolic model.

\section{Appendix 2: Numerical Model Development and Application}

\section{A2.1: Description of Numerical Code}

Finite element modeling was conducted with the Sierra simulation software.

Sierra/SolidMechanics is a general purpose massively parallel nonlinear solid mechanics finite element code for explicit transient dynamics, implicit transient dynamics and quasi-static analysis of structures. It is based on an extensive suite of element, material, contact and solver libraries for analyzing the nonlinear mechanical response of solids subjected to loadings. Sierra/Solid Mechanics VOTD User's Guide (SIERRA Solid Mechanics Team, 2011) describes these capabilities in detail.

Mean quadrature, linear midpoint-increment integrated hex-8 elements were used for the model mesh generation. This element was chosen due to its ubiquitous use and reputability in 3-Dimensional FEA analysis in addition to an ability to capture the simple/uniform laboratory wellbore curvature upon refinement of the brick geometry. Modeling the joint interface between materials, such as for the cement-casing interfacial contact, required development of similar meshes for both frictional and nonfrictional simulations. To accomplish this, surfaces remained un-merged during mesh generation and contact was specified as an input model parameter.

A perfect bond was desired between the steel-cement interface of the laboratory model for convergence studies to a closed-form solution as well as for implementing a 
constitutive model relationship between the microannulus interface. Therefore, tied constraints were implemented between conjugate node pairs. Finite Element Taring and Interconnecting Linear equation Solver (FETI) was used as an implicit equation solver for these simulations (SIERRA Solid Mechanics Team, 2011).

\section{$\underline{\text { A2.2 Constitutive Model for the Mechanical Response of Cement }}$}

The Kayenta constitutive model (Brannon et al., 2009) is used to model the mechanical response of cement. In the most minimalist sense, Kayenta can model simple linear elastic behavior, but with more detailed parameterization can also model complex behavior such as material softening and rate dependence of viscoplastic and pore crushing materials; hydrostatic and triaxial testing are base testing requirements to parameterize more complex behavior.

A pre-parameterized Portland cement material model in the Kayenta material repository was used as base parameters for the constitutive model in this analysis. Uniaxial unconfined compressive strength test data from an unmodified class $\mathrm{G}, 40 \%$ silica flour cement from Philippacopoulos and Berndt (2001) was chosen to calibrate the Kayenta constitutive model. Equation A.4 provides Kayenta's formulation of the shear limit surface behavior in tri-axial compression as a function of $I_{1}$, the trace and first invariant of the Cauchy stress tensor.

$F_{f}\left(I_{1}\right)=a_{1}-a_{3} e^{-a_{2} I_{1}}+a_{4} I_{1}$

To obtain a best fit to the cement behavior, Portland cement parameters obtained from the Kayenta materials database were altered from the original to final values (all else held constant) as shown in Table A.1, where B is the bulk modulus, $G$ is the shear modulus, and the ' $a$ ' terms are fitting variables to the shear limit surface in equation A.4. The cement sheath is assumed uniform and therefore characteristics such as the "wall effect" or inefficient packing of cement particles are not accounted for in this numerical model. Furthermore, no cracking of cement was considered here as cement softening after peak load was described using plasticity. 
Table A.1: Altered Portland cement parameters used in the Kayenta constitutive model.

\begin{tabular}{|c|c|c|c|}
\hline Symbol & Initial Value & Final Value & Units \\
\hline $\mathrm{B}$ & $2.2 \times 10^{9}$ & $6.0 \times 10^{9}$ & $\mathrm{~Pa}$ \\
\hline $\mathrm{G}$ & $1.7 \times 10^{9}$ & $4 \times 10^{9}$ & $\mathrm{~Pa}$ \\
\hline $\mathrm{a} 1$ & $4.26455 \times 10^{8}$ & $4.347 \times 10^{8}$ & $\mathrm{~Pa}$ \\
\hline $\mathrm{a} 2$ & $7.51 \times 10^{-10}$ & $7.51 \times 10^{-10}$ & $\frac{1}{\mathrm{~Pa}}$ \\
\hline $\mathrm{a} 3$ & $4.19116 \times 10^{8}$ & $4.20 \times 10^{8}$ & $\mathrm{~Pa}$ \\
\hline $\mathrm{a} 4$ & $1.0 \times 10^{-10}$ & $1.0 \times 10^{-10}$ & Dimensionless \\
\hline
\end{tabular}

A model of a cylindrical specimen was created from a mesh of 20,700 eight-node hexahedra elements. The cylinder has a radius of $38 \mathrm{~mm}$, height of $76 \mathrm{~mm}$, and was loaded under a displacement control of 3.81E-6 m/sec (initial axial displacement of $1.798 \mathrm{~mm}$ over 472 seconds). The maximum axial stress and strain of the cylinder block were obtained at each time-step.

A comparison of experimental data and the finite element results are shown in Figure A.2. The finite element results yield a moderately higher peak axial stress than the laboratory data. Additionally, the finite element post-peak behavior softens somewhat differently than the laboratory data, but within close range of the absolute strain value.

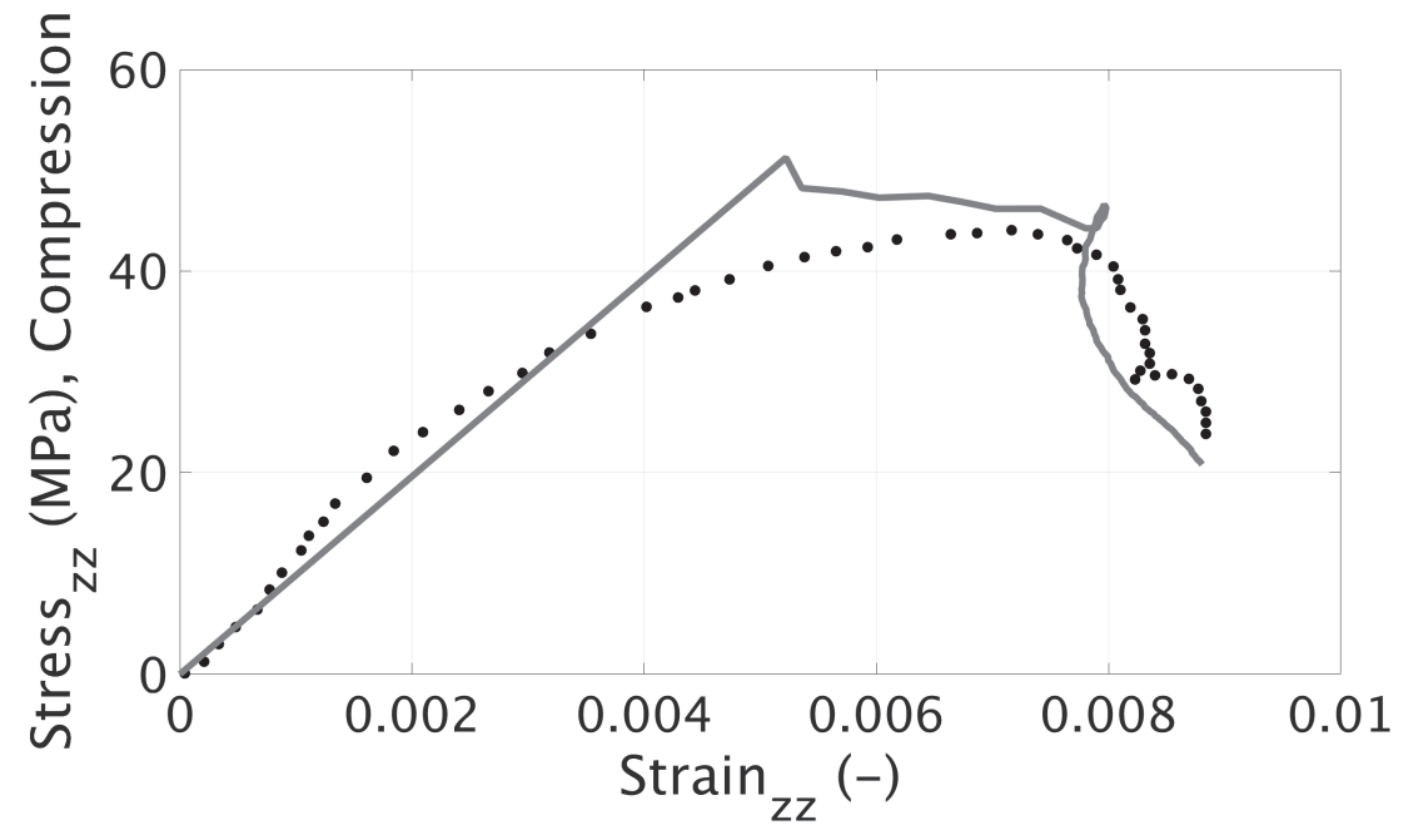

Figure A.2: FEA constitutive model (solid line) fit to Phillippacopoulos and Berndt (2001) experimental data for a cement specimen undergoing uni-axial compression. 


\section{A2.3: Verification: Convergence Study}

The appropriate mesh size was determined by mesh refinement studies on five meshes ranging from 114 elements to 4,670,000 elements. Convergence was determined by comparing the numerical results to an analytical elastic solution of two nested hollow cylinders (Ugwu, 2008), herein referred to as the bi-material solution. In the analytical solution, the cement sheath is treated as a thick walled pressure vessel and the steel casing as a thin walled pressure vessel (Ugwu, 2008). Convergence with the analytical solution was obtained with a mesh consisting of 466,000 elements, and this model was used for subsequent analysis of the laboratory wellbore conditions. A perfectly bonded casing-cement interface was enforced through tied contact in convergence testing. The elastic material properties for convergence studies are shown in Table 2. As shown in Figure A.3, the radial stress at the outer cement sheath shows convergence within less than $1 \%$ error against the analytical bi-material solution. Further mesh discretization beyond this element size does not improve the solution accuracy.

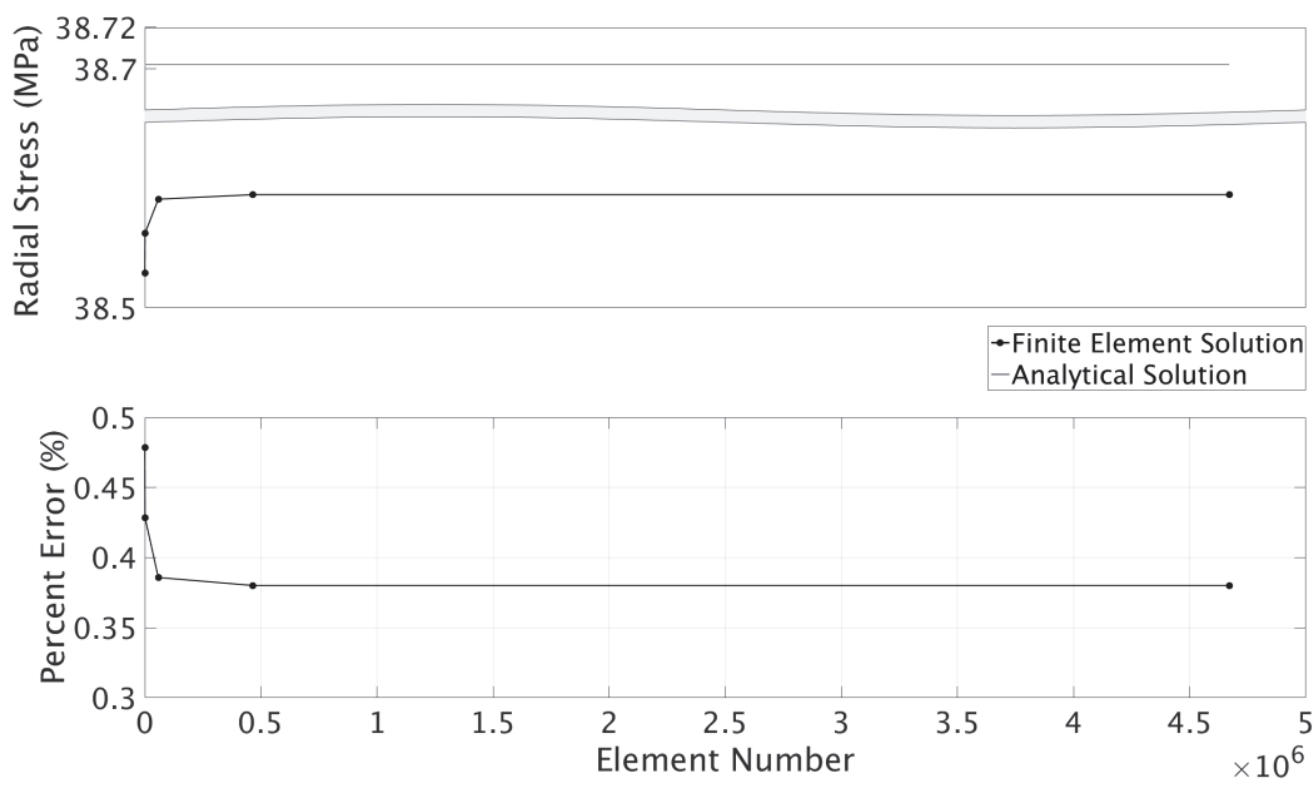

Figure A.3: Radial stress plotted over the number of elements during mesh refinement for the bi-material laboratory wellbore subjected to an internal pressure of $20 \mathrm{MPa}$ and an external pressure of $30 \mathrm{MPa}$. Convergence within $1 \%$ error is obtained upon mesh refinement.

To evaluate convergence along the radial distance of the laboratory wellbore, elements were chosen from the inner surface of the cement sheath and outer radius of the cement sheath wall, denoted as radius " $c$ " and "d" respectively in Figure 5. Figure A.4 shows the results of the convergence study along with the analytical solution as function of distance in the cement sheath. 

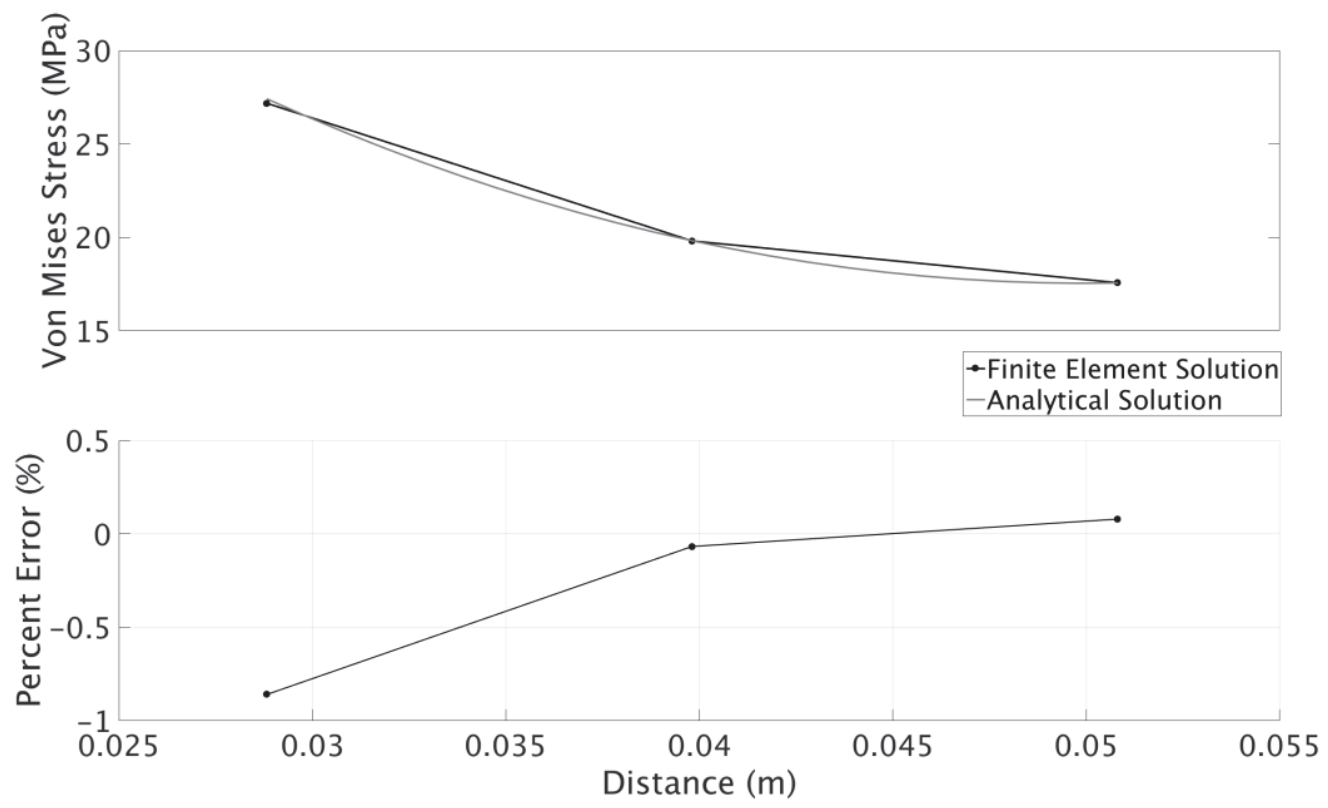

Figure A.4: Von Mises stress along the inner edge to outer edge of the cement sheath of a bi-material laboratory wellbore subjected to an internal pressure of $20 \mathrm{MPa}$ and an external pressure of $30 \mathrm{MPa}$. Convergence within $1 \%$ error is shown along this radius.

It can be observed in Figure A.4 that analytical convergence was obtained within less than $1 \%$ error for the Von Mises stress. To be comparable to the bi-material solution, the convergence studies used linear-elastic material models for the cement sheath and steel casing. Parametric studies are subsequently conducted using an identical converged mesh, but with both linear and non-linear material models. 


\section{$\underline{\text { References }}$}

Bachu, S. and Bennion, D.B., 2009. Experimental assessment of brine and/or $\mathrm{CO}_{2}$ leakage through well cements at reservoir conditions. In: Int. J. Greenhouse Gas Cont., 3, 494501.

Bandis, S.C., Lumsden, A.C., and Barton, N.R., 1983. Fundamentals of rock joint deformation. In: International Journal of Rock Mechanics and Mining Sciences \& Geomechanics Abstracts. Vol. 20. 6. Elsevier, pp. 249-268.

Jacob, B., 2013. Dynamics of fluids in porous media. Courier Corporation.

Bellabara, M., 2008. Ensuring Zonal Isolation Beyond the Life of the Well. Oilfield Review, Spring, $8-31$.

Bois, A.P., Garnier, A., Galdiolo, G., and Laudet, J.B., 2012. Use of a mechanistic model to forecast cement-sheath integrity. In: SPE Drilling \& Completion 27.02, pp. 303-314.

Brannon, R., Fossum, A., and Strack, O., 2009. KAYENTA: Theory and User's Guide. In: Sandia Report. Vol. 2009-2282. Sandia National Labs, p. 186.

Carey, J.W., Lewis, K., Kelkar, S., and Zyvoloski, G.A., 2013. Geomechanical Behavior of Wells in Geologic Sequestration. In: Energy Procedia 37, pp. 5642-5652.

Forchheimer, P., 1901. Wasserbewegung durch Boden, Zeitz ver Deutch Ing., 45, 17821788.

Gasda, S.E., Bachu, S., and Celia, M.A., 2004. Spatial characterization of the location of potentially leaky wells penetrating a deep saline aquifer in a mature sedimentary basin. In: Environmental geology October 2004, Volume 46, Isssue 6, pp. 707-720.

Gray, K.E., Podnos, E., and Becker, E., 2009. Finite-element studies of near-wellbore region during cementing operations: Part I. In: SPE Drilling \& Completion 24.1, p. 127.

Hawkes, C.D., McLellan, P.J., and Bachu, S., 2005. Geomechnical Factors Affecting Geological Storage of $\mathrm{CO}_{2}$ in Depleted Oil and Gas Reservoirs. J. Can. Petr.Tech. 44 (10), $2-61$.

Iwai, K., 1976. Fundamental studies of fluid flow through a single fracture. PhD thesis. University of California, Berkeley.

Kutchko, B.G., Strazisar, B.R., Dzombak, D.A., Lowry, G.V., and Thaulow, N., 2007. Degradation of well cement by $\mathrm{CO}_{2}$ under geologic sequestration conditions. In: Environmental science \& technology 41.13, pp. 4787-4792. 
Lavrov, A., Todorovic, J., and Torsaeter, M., 2015. Numerical study of tensile thermal stresses in a casing-cement-rock system with heterogeneities, Proceedings of the 49th US Rock Mechanics / Geomechanics Symposium. San Francisco, CA, June 28 - July 1, paper ARMA 15-110.

Martinez, M., Newell, P., Bishop, J.E., and Turner, D.Z., 2013. Coupled multiphase flow and geomechanics model for analysis of joint reactivation during $\mathrm{CO}_{2}$ sequestration operations. In: International Journal of Greenhouse Gas Control 17, pp. 148-160.

Matteo, E.N. and Scherer, G.W., 2012. Experimental study of the diffusion controlled acid degradation of Class H Portland cement. In: International Journal of Greenhouse Gas Control 7, pp. 181-191.

Nordbotten, J.M., Celia, M., and Bachu, S., 2004. Analytical solutions for leakage rates through abandoned wells. In: Water Resources Research 40.4.

Nordbotten, J.M., Celia, M., and Bachu, S., 2005a. Injection and storage of $\mathrm{CO}_{2}$ in deep saline aquifers: Analytical solution for $\mathrm{CO}_{2}$ plume evolution during injection. In: Transport in Porous media 58.3, pp. 339-360.

Nordbotten, J.M., Celia, M., Bachu, S., and Dahle, H. ,2005b. Semianalytical solution for $\mathrm{CO}_{2}$ leakage through an abandoned well. In: Environmental science \& technology 39.2, pp. 602-611.

Orlic, B., 2008. Some Geomechanical Aspects of Geological $\mathrm{CO}_{2}$ Sequestration. In Proceeding of the 12th International Conference of International Association for Computer Methods and Advances in Geomechanics , Goa, India, 1-6 October, 2204 2212.

Philippacopoulos, A.J. and Berndt, M.L., 2001. Mechanical property issues for geothermal well cements. In: Transactions Geothermal Resources Council, pp. 119-124.

Renshaw, C.E., 1995. On the relationship between mechanical and hydraulic apertures in rough-walled fractures. In: Journal of Geophysical Research: Solid Earth (1978-2012) 100.B12, pp. 24629-24636.

Schreppers, G., 2015. A framework for wellbore cement integrity analysis. ARMA 15349 Proceedings of the 49th US Rock Mechanics-Geomechanics Symposium, San Francisco, CA, USA. American Rock Mechanics Association.

Seidel, F.A. and Greene, T.G., 1985. Use of Expanding Cement Improves Bonding and Aids in Eliminating Annular Gas Migration in Hobbs Grayburg-San Andres Wells. Paper SPE 14434 presented at the SPE Annual Technical Conference and Exhibition, Las Vegas, Nevada, USA, 22-25 September. DOI: 10.2118/14434-MS. 
SIERRA Solid Mechanics Team, 2011. Sierra/SolidMechanics 4.22 User's Guide. SAND Report 2011-7597. Albuquerque, NM and Livermore, CA: Sandia National Laboratories.

Souley, M., Homand, F., and Amadei, B.,(1995). An extension to the Saeb and Amadei constitutive model for rock joints to include cyclic loading paths. In: International journal of rock mechanics and mining sciences $\&$ geomechanics abstracts. Vol. 32. 2. Elsevier, pp. 101-109.

Stormont, J.C., Ahamd, R., Ellison, J., Reda Taha, M.M., and Matteo, E.N., 2015. Laboratory measurements of flow through wellbore cement-casing microannuli. In: ARMA 15-294, Proceedings of the 49th US Rock Mechanics-Geomechanics Symposium, San Francisco, CA, USA. American Rock Mechanics Association.

Ugwu, I.O., 2008. Cement fatigue and HPHT well integrity with application to life of well prediction. PhD thesis. Texas A\&M University.

Witherspoon, P.A., Wang, J.S., Iwai, K., Gale, J.E., 1980. Validity of cubic law for fluid flow in a deformable rock fracture. Water Res. Res. 16 (6), 1016-1024.

Zhang, M. and Bachu, S., 2011. Review of integrity of existing wells in relation to $\mathrm{CO}_{2}$ geological storage: What do we know? Int. J. Greenhouse Gas Cont. 5, 826-840. 